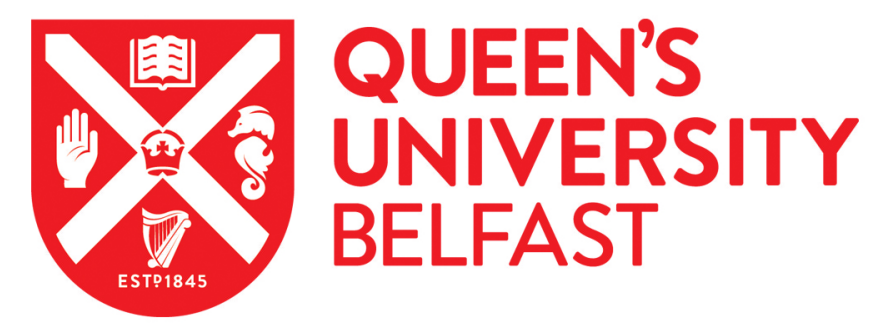

\title{
Fibre reinforced polymer for strengthening cylindrical metal shells against elephant's foot buckling: An elasto-plastic analysis
}

Batikha, M., Chen, J. F., \& Rotter, J. M. (2018). Fibre reinforced polymer for strengthening cylindrical metal shells against elephant's foot buckling: An elasto-plastic analysis. Advances in Structural Engineering, 21(16), 2483-2498. https://doi.org/10.1177/1369433218817139

Published in:

Advances in Structural Engineering

Document Version:

Peer reviewed version

Queen's University Belfast - Research Portal:

Link to publication record in Queen's University Belfast Research Portal

Publisher rights

Copyright 2018 SAGE. This work is made available online in accordance with the publisher's policies. Please refer to any applicable terms of use of the publisher.

\section{General rights}

Copyright for the publications made accessible via the Queen's University Belfast Research Portal is retained by the author(s) and / or other copyright owners and it is a condition of accessing these publications that users recognise and abide by the legal requirements associated with these rights.

Take down policy

The Research Portal is Queen's institutional repository that provides access to Queen's research output. Every effort has been made to ensure that content in the Research Portal does not infringe any person's rights, or applicable UK laws. If you discover content in the Research Portal that you believe breaches copyright or violates any law, please contact openaccess@qub.ac.uk. 


\title{
FRP for Strengthening Cylindrical Metal Shells against Elephant's Foot Buckling - An Elasto-Plastic Analysis
}

\author{
M. Batikha ${ }^{1}$, J.F. Chen ${ }^{2,3, *}$ and J.M. Rotter ${ }^{4}$
}

1. Assistant Professor, School of Energy, Geoscience, Infrastructure and Society, Heriot-

Watt University-Dubai Campus, Dubai, UAE

2. Distinguished Professor, College of Architecture and Civil Engineering, Wenzhou

University, Wenzhou, China

3. Professor, School of Natural and Built Environment, Queen's University Belfast, Belfast BT9 5AG, UK

4. Emeritus Professor, School of Engineering, The University of Edinburgh, Edinburgh EH9 3JL, UK

* Corresponding author. Email: j.chen@qub.ac.uk, tel. +44 2890974184

\begin{abstract}
:
This paper describes the use of Fibre Reinforced Polymer (FRP) composites to increase the strength of an isotropic metallic cylindrical shell against elephant's foot buckling. This form of buckling occurs when a cylindrical shell structure is subjected to high internal pressure together with an axial force, such as those that may occur in tanks and silos. It is particularly relevant to tanks under seismic action. Although FRP composites have been widely applied to different types of structures under several loading conditions, its use to strengthen thin steel cylindrical shells has been very limited. Here, a non-linear elasto-plastic finite element idealization is used to explore the strengthening effect of an FRP strip on a thin cylinder. The optimum size and position of the FRP sheet were obtained and empirically formulated. This study has shown that the strength after repair is sensitive to minor changes in the FRP-parameters so that a close adherence to the optimum parameter values is very desirable.
\end{abstract}

Keyword: Elephant's foot buckling, FRP, shells, strengthening, non-linear analysis, silos, tanks.

\section{Introduction}

Elephant's foot is the term commonly used to describe a local elastic-plastic buckling failure that occurs at the base of a cylindrical shell structure that is subjected to high internal pressure together with an axial force. This type of buckling failure is common in tanks after they have been damaged by earthquakes due to the axial forces induced by overturning moments (Rotter, 1990, 2006). Cyclic loading may cause an elephant's foot buckle to extend around the complete circumference at the bottom of the tank wall (Subhan et al., 2017; Djermane et al., 2014). Elephant's foot buckling can also be predicted for non-empty thin silos under wind loads (Zhao et al., 2013; Cao et al., 2018). A local buckle forms adjacent to the boundary, where the effects of local bending are amplified by co-existent axial compression (Rotter, 1989). It may be noted that smaller internal pressures increase the buckling strength under axial compression (Teng and 
Rotter 1992; Rotter 2004), but the first demonstration that this effect is limited by elephant's foot buckling was given by Rotter (1990).

The first theoretical investigation of elephant's foot buckling for both pinned-base and fixed-base cylinders was published by Rotter (1990). His proposed semi-empirical design expressions are now widely used in codes of practice (EN 1993-1-6, 2007; EN 1993-4-1, 2007; EN 1998-4, 2006; NZS-2654, 1989). Rotter showed that a clamped base can provide a significant increase in strength in very thin cylinders; but that the strength is similar for both pinned and fixed bases in thicker cylinders. An alternative treatment for design purposes was also developed by Rotter (2006). More recently, Kildashti et al. (2018) showed by a nonlinear time history analysis that there seems to be little difference in buckling resistance between the pinned and fixed base conditions if the tank is susceptible to elephant 's foot buckling under dynamic loading.

One technique to strengthen a cylindrical tank or silo against elephant's foot buckling is to use a ring stiffener. Chen et al. $(2005,2006)$ proposed that a small discrete metal ring stiffener could considerably improve a tank's resistance to elephant's foot buckling. The optimum dimensions and location for this stiffener were derived, based on linear elastic shell bending theory (Timoshenko and Woinowsky-Krieger 1959; Rotter, 1985a). It was shown that if the ring stiffener has either a size or a location different from the optimum condition, the enhancement in the buckling strength that it provides can easily be lost.

External bonding of fibre reinforced polymer (FRP) composites have been an effective strengthening method for different types of structures under various loading scenarios (Teng et al 2002, Teng and Chen 2009). Kumar and Senthil (2016a; b) investigated the behaviour of an FRP-strengthened slender element of steel circular hollow sections (CHS) under axial loading, and observed a significant improvement in ductility, stiffness, and loading capacity. The loading capacity and the energy dissipation of concrete-filled steel cylinders under axial and lateral loadings can also be significantly enhanced by confining them with FRP ( $\mathrm{Lu}$ et al, 2014; Zhu et al, 2018). In this case the steel tube wall is under internal pressure due to the expansion of concrete which also prevents its inward buckling, while its outwards buckling is restrained by the FRP. However, there is still very little published work on FRP-strengthened thin steel cylinders (Teng et al., 2012).

Teng and Hu $(2004,2007)$ studied the wrapping of thicker cylinders $(R / t=19)$ with FRP to resist axisymmetric plastic buckling failures under pure axial compression (also described as elephant's foot, although the conditions are slightly different from those found in tanks and silos). Batikha et al. (2007a; 2009) studied a thin silo $(R / t=1000)$ strengthened by FRP against elephant's foot buckling under an axial load accompanied by internal pressure. In that study the optimum location and size of the FRP strengthening were derived using an elastic analysis. However, the accuracy of that study may be limited since plasticity could play a significant role in elephant's foot buckling. The present study thus extends the work presented in Batikha et al. (2007a; 2009) by adopting a Geometrically and Materially Non-linear Analysis (GMNA) to devise proposals that accurately describe the great benefits of FRP in preventing elasto-plastic collapse at a tank base. It may be noted that the preliminary results of this study were presented in a conference (Batikha et al. 2007b), where it was shown that FRP is an effective remedy. 


\section{Finite element modelling}

The general-purpose finite element program ABAQUS (Ver 6.12-1) was used for the analysis. A steel cylinder with a height $h$ of $5000 \mathrm{~mm}$, radius $R$ of $5000 \mathrm{~mm}$ and thickness $t_{s}$ of $5 \mathrm{~mm}$ was modelled as the reference case. The radius to thickness ratio $R / t$ was 1000 , producing a mediumlength cylinder according to EN 1993-1-6 (2007). The values of Young's modulus, $E_{s}$, and Poisson's ratio, $v_{s}$, of the steel were taken as $200 \mathrm{GPa}$ and 0.3 respectively. The steel was assumed to have an elastic-perfectly-plastic stress-strain relationship with a yield stress of $f_{y}=$ $250 \mathrm{~N} / \mathrm{mm}^{2}$.

A uniform internal pressure $p$ and a vertical load per unit circumference $N_{z}$ were applied to the cylinder. The base of the cylinder was restrained in the radial and axial directions. The top edge of the cylinder was restrained against rotation. Under axisymmetric loading, these boundary conditions ensure that buckling occurs at the base and model a cylinder that is much longer than the extent of the local deformations involved in elephant's foot buckling (Rotter and Teng, 1989).

The cylinder was modelled using the 2-node axisymmetric general-purpose shell element SAX1 which includes transverse shear deformation (ABAQUS/Standard User's Manual, 2012). Each node has three degrees of freedom (radial and axial displacements and rotation about the circumferential axis). An axisymmetric element was justified as only axisymmetric collapse was observed in previous studies that included checks for non-symmetric bifurcation (Rotter, 1990, 2006).

Non-linear elasto-plastic finite element analysis was performed. The Riks arc-length method was used (Riks 1979) to trace the nonlinear response after buckling. A mesh convergence study was conducted, from which an element size of $0.02 \sqrt{R t_{S}}$ was chosen. Such an element size is far smaller than that used by Rotter and Teng (1989) and Rotter and Zhang (1990), where cubic elements of size $0.25 \sqrt{R t_{s}}$ were used.

\section{Buckling strength of thin cylindrical shells without strengthening}

For a uniform metal cylindrical shell without any strengthening to resist elephant's foot buckling, an upper bound to the strength may be taken as the condition where the von Mises effective stress is reached on the outside surface of the shell:

$$
\sigma_{v M}=\sqrt{\left(\sigma_{m z}+\sigma_{b z}\right)^{2}-\left(\sigma_{m z}+\sigma_{b z}\right) \times\left(\sigma_{m \theta}+v \sigma_{b z}\right)+\left(\sigma_{m \theta}+v \sigma_{b z}\right)^{2}}
$$

in which $\sigma_{m z}$ is the meridional membrane stress, $\sigma_{m \theta}$ is the circumferential membrane stress, and $\sigma_{b z}$ is the meridional bending stress. The latter two stresses are usually dominant in Eq. (1) when the internal pressure is high. The von Mises stress, $\sigma_{v M 0}$ is used as the reference value, which 
refers to the state where the bending moment is zero and the lateral displacement, $w$, is equal to the membrane theory normal deflection $w_{m}$ :

$$
w_{m}=\left(p+\frac{v_{s} N_{z}}{r}\right) \frac{r^{2}}{E_{s} t_{s}}
$$

The axial stress at first yield when the characteristic elephant's foot shape develops can be predicted by Rotter's (1989) approximation to the exact solution for the non-linear elastic bending equations:

$$
\sigma v M_{\max }=\left(\frac{P R}{t}+0.3 \sigma_{m z}\right)\left(2.725+\frac{1+0.55 \sigma}{\sqrt{1-\sigma^{2}}}\right)-2.65 \frac{P R}{t}=f_{y}
$$

in which the normalised meridional membrane stress:

$$
\sigma=\frac{\sigma_{m z}}{\sigma_{c l}}
$$

where $\sigma_{c l}$ is the classical elastic buckling stress of thin cylindrical shells given by:

$$
\sigma_{c l}=\frac{E}{\sqrt{3\left(1-v^{2}\right)}} \frac{t}{R} \approx 0.605 E \frac{t}{R}
$$

Rotter $(1989,1990)$ derived the following semi-empirical equations to describe the elephant's foot buckling strength under elastic-plastic conditions. These have been widely adopted into codes of practice (e.g. EN 1993-1-6, 2007; ECCS, 2008):

$$
\begin{aligned}
& \sigma_{m z}=\sigma_{c l}\left[1-\left(\frac{P R}{t f_{y}}\right)^{2}\right]\left(1-\frac{1}{1.12+\rho^{1.5}}\right)\left[\frac{\rho+\frac{f y}{250}}{\rho+1}\right] \\
& \rho=\frac{1}{400} \frac{R}{t}
\end{aligned}
$$

The conditions leading to elastic bifurcation buckling under pure axial compression in other parts of an imperfect shell have been reviewed by Rotter (2004) and are defined in EN 1993-1-6 (2007). The amplitude of the imperfection affects this strength, and the reduced strength is commonly written as:

$$
\sigma_{m z}=\sigma_{c l} \cdot \alpha_{z}
$$

where $\alpha_{z}$ is the meridional elastic imperfection factor. An empirical lower bound for the relationship between this imperfection factor and the imperfection amplitude is used in EN 1993-1-6 (2007) as:

$$
\alpha_{z}=\frac{0.62}{1+1.91\left(\Delta w_{k} / t\right)^{1.44}}
$$

in which $\Delta w_{k}$ is the characteristic imperfection amplitude. Since the imperfection amplitude is affected by both the quality of fabrication and the radius to thickness ratio, the amplitude is defined in EN 1993-1-6 (2007), taken from Rotter (1985b), as:

$$
\frac{\Delta w_{k}}{t}=\frac{1}{Q} \sqrt{\frac{R}{t}}
$$

where, $Q$ is the meridional compression fabrication quality parameter (Table 1). 
Table 1. The meridional compression fabrication quality parameter, $Q$ (EN 1993-1-6, 2007; Rotter, 1985b, 2004).

Fabrication tolerance quality clas

Description Q

\begin{tabular}{lcc}
\hline Class A & Excellent & 40 \\
Class B & High & 25 \\
Class C & Normal & 16 \\
\hline
\end{tabular}

In Table 1, the quality class (A, B or C) of a constructed shell can be determined by tolerance measurements to check the out-of-roundness, the accidental eccentricities, initial dimples and interface flatness of a cylindrical shell. These measurements are described in EN 1993-1-6 (2007).

Figure 1 shows the buckling strength predictions defined by the above equations for a cylindrical shell with a radius to thickness ratio $R / t$ of 1000 , under vertical load producing the vertical membrane stress $\sigma_{m z}$ accompanied by internal pressure $p$.

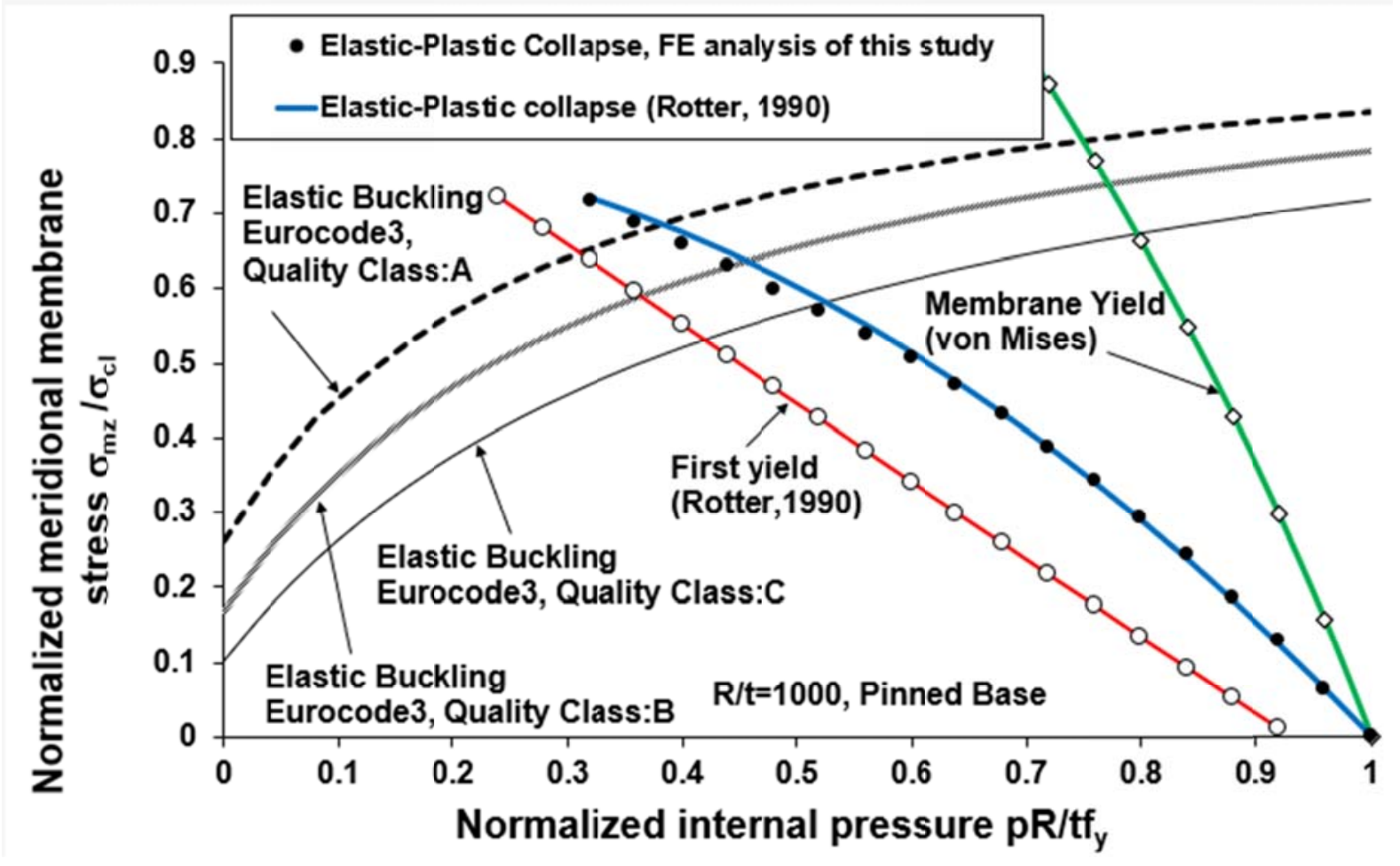

FIG. 1. Collapse predictions for a pinned cylindrical shell with $R / t=1000$.

Figure 1 shows that the buckling strength increases with an increase of the internal pressure. However, beyond a certain value of the internal pressure, yielding of the wall occurs, leading to a local reduction in the flexural stiffness, increased displacement and circumferential membrane stress resultants (Rotter 1989) and ultimately elastic-plastic buckling (Rotter 1990). At the cylinder base, this elastic-plastic instability failure is known as elephant's foot buckling. Figure 
1 shows that the elastic-plastic collapse strengths obtained from a FE analysis in the present study are in very close agreement with those predicted by Eq. 6 developed by Rotter (1990).

\section{FRP strengthened cylindrical shells}

\subsection{Modelling}

For the example cylinder, an FRP sheet with a height of $h_{f}$ was bonded to the external surface of the cylindrical shell, starting at the level $x_{f}$ above the base. The FRP sheet was treated as orthotropic with Young's modulus $E_{f \theta}$ in the circumferential direction and $E_{f z}$ in the meridional direction, and Poisson's ratios $v_{\mathrm{f} \theta \mathrm{z}}$ and $v_{\mathrm{fz} \theta}$. The FRP lamina was modelled using the element SAX1, a 2-node axisymmetric shell element. The model assumed a perfect bond between the cylinder and the FRP sheet.

\subsection{Verification of the model}

To verify the FE model, the FE predictions are compared with the experimental results of Teng and $\mathrm{Hu}(2004,2007)$ as shown in Fig. 2. The experimental study of Teng and Hu $(2004,2007)$ was to demonstrate the effectiveness of FRP confinement on thick steel tubes using a GFRP jacket. The experimental setup of a fixed-base steel tube with height $h=450 \mathrm{~mm}$, radius $R=$ $80.4 \mathrm{~mm}$ and thickness $t_{s}=4.2 \mathrm{~mm}$ was modelled. The steel had a Young's modulus $E_{s}$ of $201 \mathrm{GPa}$, Poisson's ratio $v_{s}$ of 0.3 and yield stress of $335 \mathrm{MPa}$ with strain hardening modulus of $5 \%$ of the elastic value. It should be noted that the tube is considered thick, with an $\mathrm{R} / \mathrm{t}$ ratio of about 19 . The $0.53 \mathrm{~mm}$ thick $\left(t_{f}\right)$ three-ply GFRP jacket was modelled over the entire height of the tube as in the experiment. The GFRP sheet was modelled as an orthotropic material with $E_{f \theta}=80.1 \mathrm{GPa}, E_{f z}=3 \mathrm{GPa}, v_{f \theta z}=0.35$ and $v_{f z}=0.013$.

It is worth mentioning that Teng and Hu modelled their tests using the B33 element in ABAQUS (Version 6.12-1) oriented in the hoop direction to model the FRP and S4R shell elements to model the tube. B33 is a bi-cubic beam element with six degrees of freedom per node. The height of the B33 element was taken as the height of the shell element. S4R is 4-node doubly curved general-purpose shell, with reduced integration with hourglass control and the effect of transverse shear deformation included. Each node has six degrees of freedom, comprising of three displacements and three rotations.

Figure 2 shows the experimental load-deflection curves for a pair of experiments with and without GFRP strengthening. The test loading capacity was $782.2 \mathrm{kN}$ for the former and 717.5 $\mathrm{kN}$ for the latter. The finite element curves of Teng and $\mathrm{Hu}$ are also shown, together with the curves predicted from the FE model in this study. Teng and Hu modelled the GFRP using beam elements and predicted a loading capacity of 800 and $709 \mathrm{kN}$ respectively for the specimens with and without FRP strengthening. The GFRP was modelled using shell elements here and the predicted corresponding loading capacities were 787 and $709 \mathrm{kN}$ respectively when the vertical stiffness of the FRP was neglected $\left(E_{f z}=0\right)$. Clearly the loading capacities predicted by both FE models are very close to the test values. All results show that the GFRP strengthening increased 
the strength of the steel tube by about $14 \%$ and enhanced the ductility by comparison with the sudden collapse in the un-strengthened case. Furthermore, a slightly higher collapse load was predicted when the axial stiffness of the FRP sheet is included.

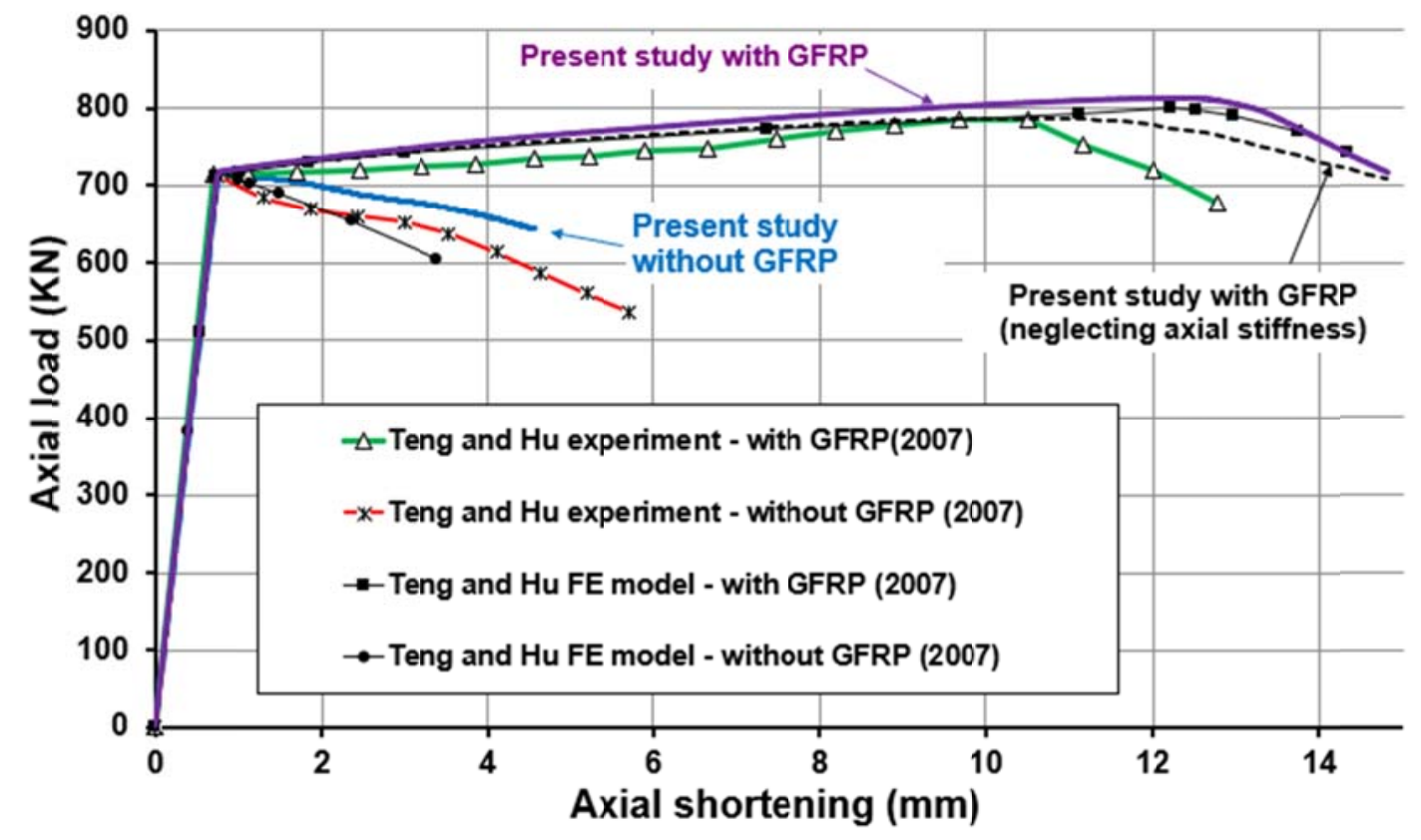

FIG. 2. Load-axial shortening of a thick cylindrical tube.

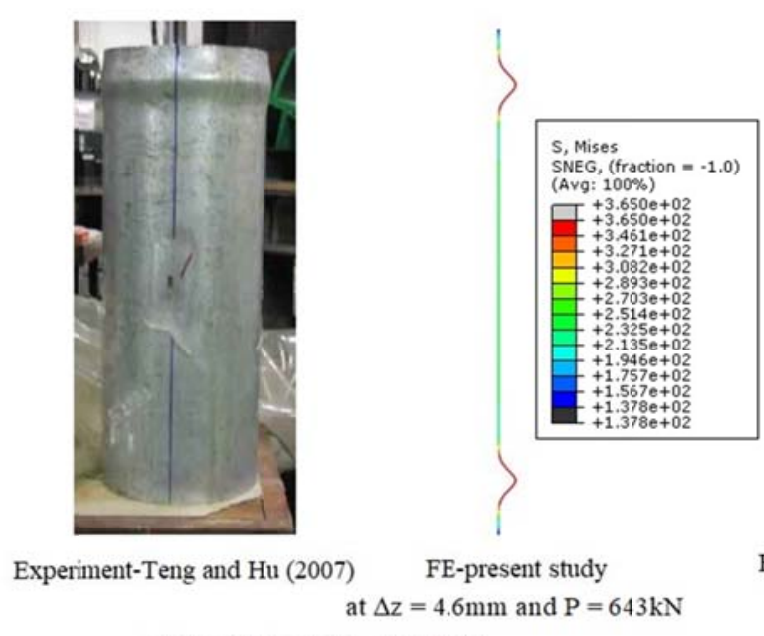

a) Steel tube-without GFRP
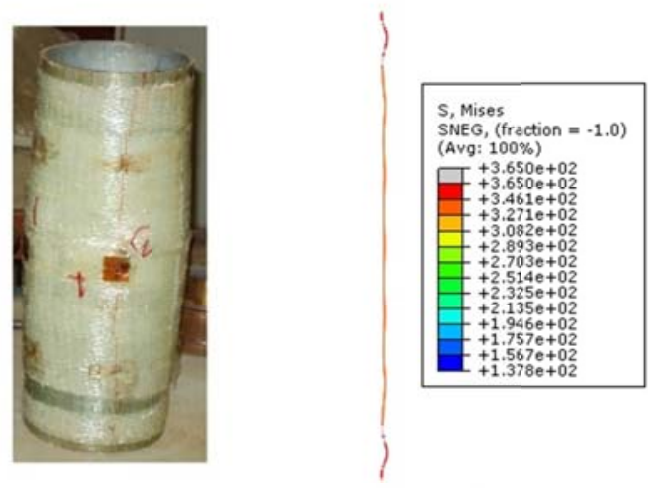

Experiment-Teng and $\mathrm{Hu}(2007) \quad$ FE-present study at $\Delta \mathrm{z}=14.8 \mathrm{~mm}$ and $\mathrm{P}=716 \mathrm{kN}$

b) Steel tube-with GFRP

FIG. 3. FE predicted vs experimental failure mode.

Figure 3 shows that the experimental and predicted deflected shapes of the cylinder are in close agreement. For the cylinder without FRP, a clear elephant's foot buckle is seen at both ends, 
whereas the GFRP wrap significantly reduces this phenomenon. Fig. 3 also shows that the von Mises stress predicted by the FE shortly after the peak load is much higher in the elephant's buckling zone than elsewhere.

\subsection{Application to thin cylindrical shells}

To explore the strengthening effect of FRP on a thin cylindrical steel shell, a steel cylinder of $R / t=1000$ as described in Section 2 was analysed with an externally bonded FRP composite. The FRP was assumed to have a Young's modulus $E_{f \theta}=230 \mathrm{GPa}$ in the circumferential direction, and $E_{f z}=3 \mathrm{GPa}$ in the meridional direction. Its Poisson's ratios were $v_{f \theta z}=0.35$ and $v_{f z}=0.0045$. An internal pressure of $200 \mathrm{kPa}\left(0.2 \mathrm{~N} / \mathrm{mm}^{2}\right)$ was applied, resulting in a circumferential membrane stress equal to $66 \%$ of the membrane yield stress. Different FRP thicknesses were considered using a normalised FRP height $h_{f} \lambda=1$, in which $\lambda$ is the linear bending half wavelength:

$$
\lambda=\frac{\pi}{\left(3\left(1-v_{s}^{2}\right)\right)^{1 / 4}} \sqrt{R t_{s}}=2.444 \sqrt{R t_{s}}
$$

Note that the linear bending half-wavelength $\lambda$ here corresponds to meridional bending without the effect of the axial stress. Under axial compressive stresses that are significantly large compared with the elastic critical value (Eq. 5), the half-wavelength of bending is reduced (Rotter, 1989).

For the reference case, the FRP strip was assumed to be located directly above the base, i.e. the normalised starting level above the base $x_{f} / \lambda=0$. The quantity of FRP is here characterised by the relative circumferential membrane stiffness $\kappa$ :

$$
\kappa=\frac{E_{f \theta} t_{f}}{E_{s} t_{s}}
$$

Figure $4 \mathrm{a}$ shows the effect of $\kappa$, here termed the stiffness ratio, on the load-axial shortening relationship. The corresponding deformed shapes after buckling are shown in Fig. 4b. As $\kappa$ increases, the buckling strength initially increases (Fig. 4) but it reaches a peak at about $\kappa=0.4$. The strengthening effect is sensitive to the circumferential membrane stiffness of the FRP. Both too little and too much FRP lead to lower strengths. A small amount of FRP strengthening (e.g. $\kappa=0.2$ ) does not change the location or the form of the elephant's foot buckle (Fig. 4b) and the failure is gentle without any snap-back. However, as the stiffness ratio $\kappa$ is further increased, the deformed shape is changed, resulting in two buckles: a smaller, lower buckle in the original location within the FRP zone and a large one directly above the FRP causing a severe snap-back response. As the amount of FRP is further increased, the lower buckle is further reduced and eventually declines to zero (i.e. no buckling within the FRP strengthening). The snap-back behaviour is eliminated but the buckling capacity is steadily reduced. When $\kappa$ increases to very large values (e.g. 100), the elephant's foot buckle moves to directly above the FRP strengthened zone and the stress-axial shortening curve becomes almost parallel to the one without FRP strengthening. Such large amounts of FRP strengthening, represented by a high value of $\kappa$, has two consequences: 1) it moves the boundary restraint at the bottom of the cylinder up to where the FRP ends; and 2) the buckling capacity is slightly increased because this 'new' boundary is effectively built-in, rather than hinged as in the un-strengthened case. 


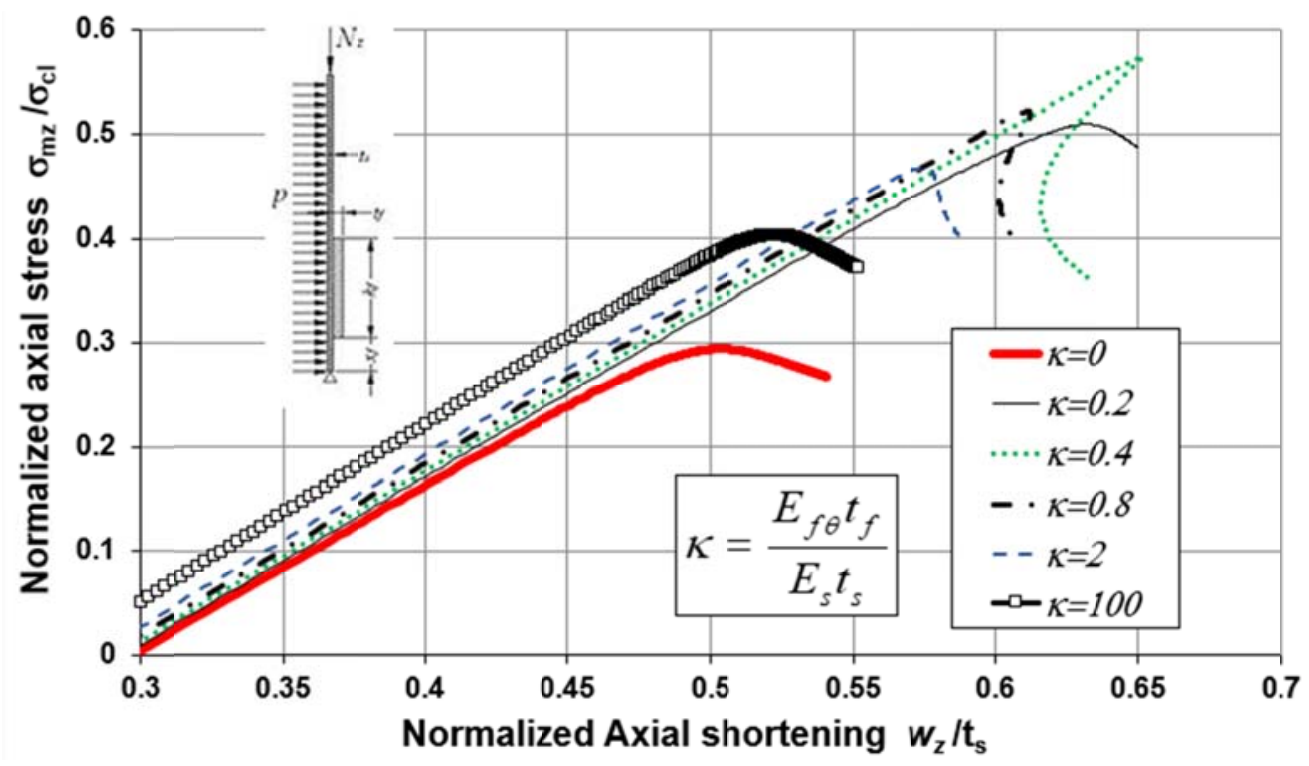

a) load - axial shortening curves

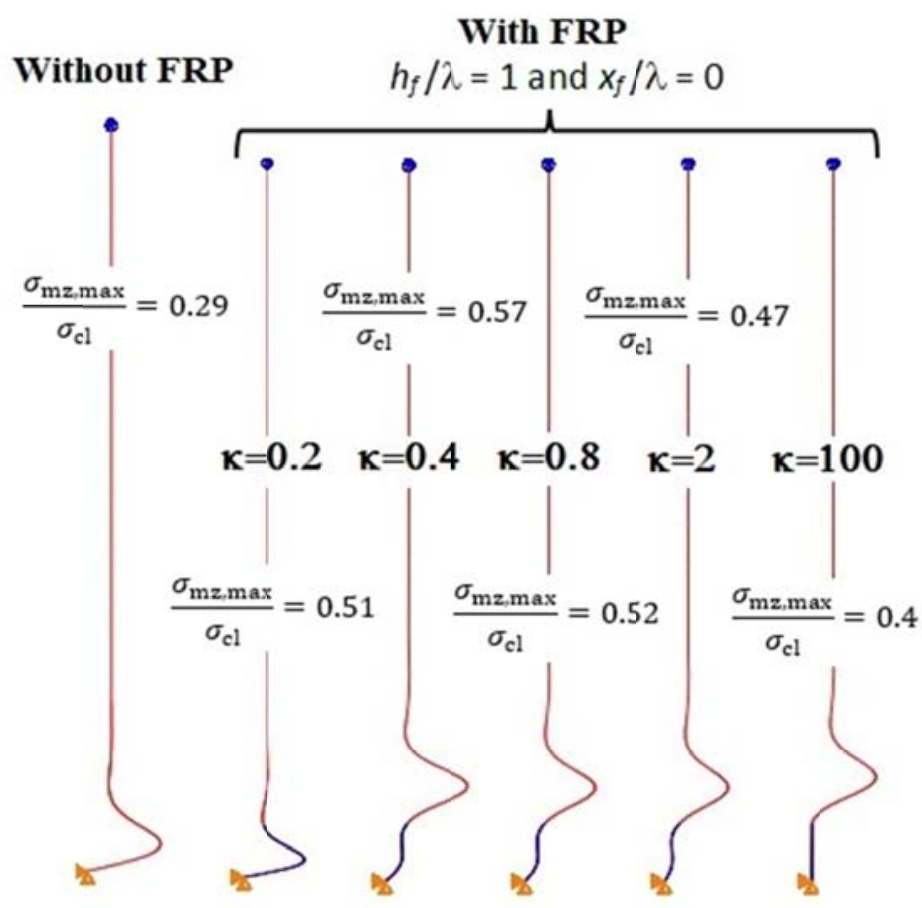

b) Deformed shapes

FIG. 4. Effect of FRP external stiffness $\left(h_{f} / \lambda=1\right.$ and $\left.x_{f} / \lambda=0\right)$.

The effect of the height of the FRP strip (height ratio $h_{f} / \lambda$ ) is shown in Fig. 5, where the FRP strip was assumed to start from the base $\left(x_{f} / \lambda=0\right)$ with the FRP stiffness parameter $\kappa=0.4$, corresponding to the optimum strengthening case in Fig. 4. The FRP height ratio also affects the strength (Fig. 5a) and the deformed shape at buckling (Fig. 5b). Clearly, there is an optimum 
height at $x_{f} / \lambda=0.75$ for this case (the optimum value may be different for different cases), which leads to the highest strength and all radial deformation being limited by the membrane deformation: no clear elephant's foot buckle is seen (Fig. 5b). The stress-axial shortening curve exhibits a strong snap-back phenomenon (Fig. 5a). For cases with the FRP height less than the optimum value, there is only one buckle, as in the common elephant's foot buckling mode (Fig. $5 b)$. As the FRP height increases to values larger than the optimum one, the strength is reduced (Fig. 5a) and two buckles appear: a lower smaller one and a larger one above the FRP strengthened zone. It is important to note that a lower strength is achieved if either a larger or a smaller height ratio than the optimum value is used.

Note that the axial shortening of the cylinder consists of two components: a) recoverable elastic shortening due to membrane stresses in the shell, and b) irrecoverable shortening due to large elasto-plastic bending deformations associated with the elasto-plastic elephant's foot buckle. The axial stress-shortening curve usually shows a gentle collapse when elasto-plastic behaviour is dominant. However, when the cylinder is strengthened with parameters equal or close to the optimum values, the bending deformation is significantly restrained, so the recoverable elastic shortening becomes dominant: the reduction in the stress also leads to a reduction of the shortening (rebounding). This is shown as the snap-back phenomenon in Fig. 5a. It is evident that such snap-back phenomena would be more significant in longer shells.

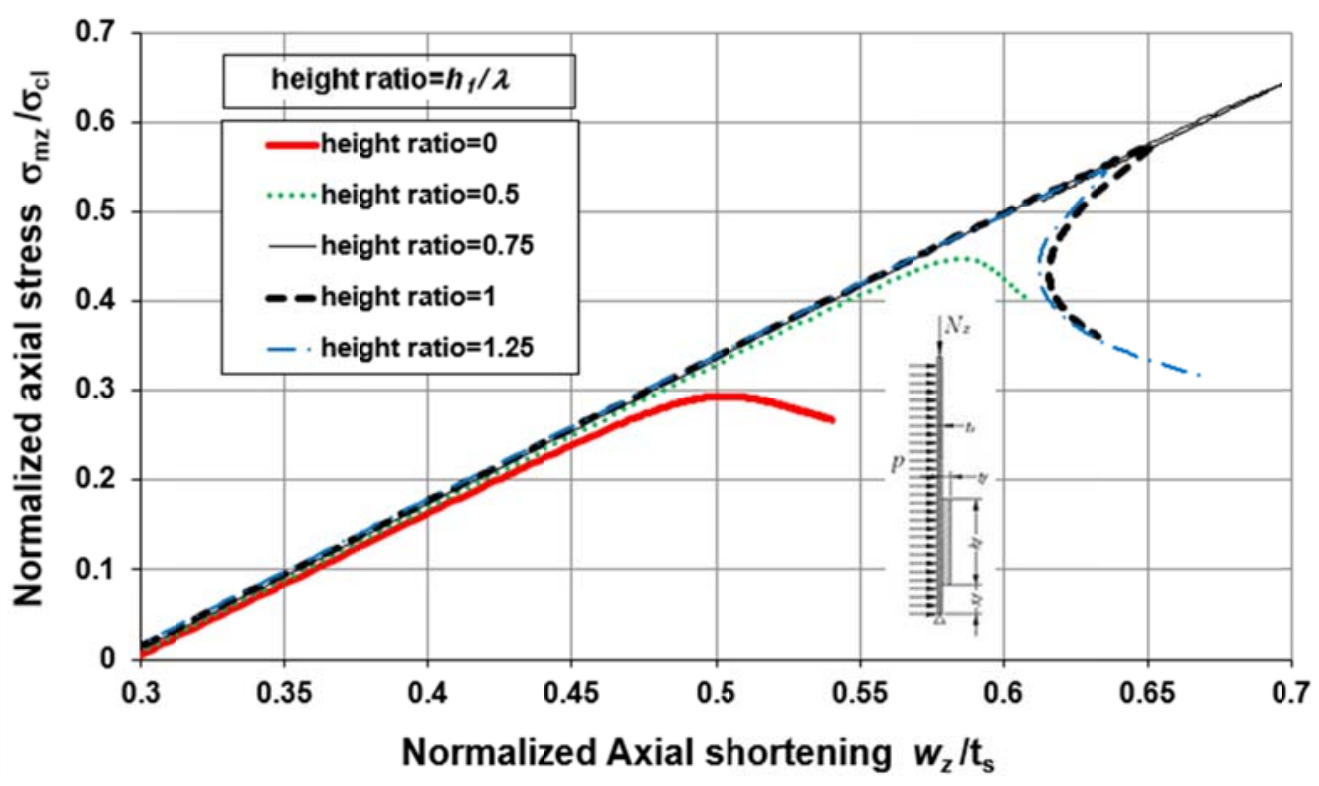

a) Axial stress - axial shortening curves 


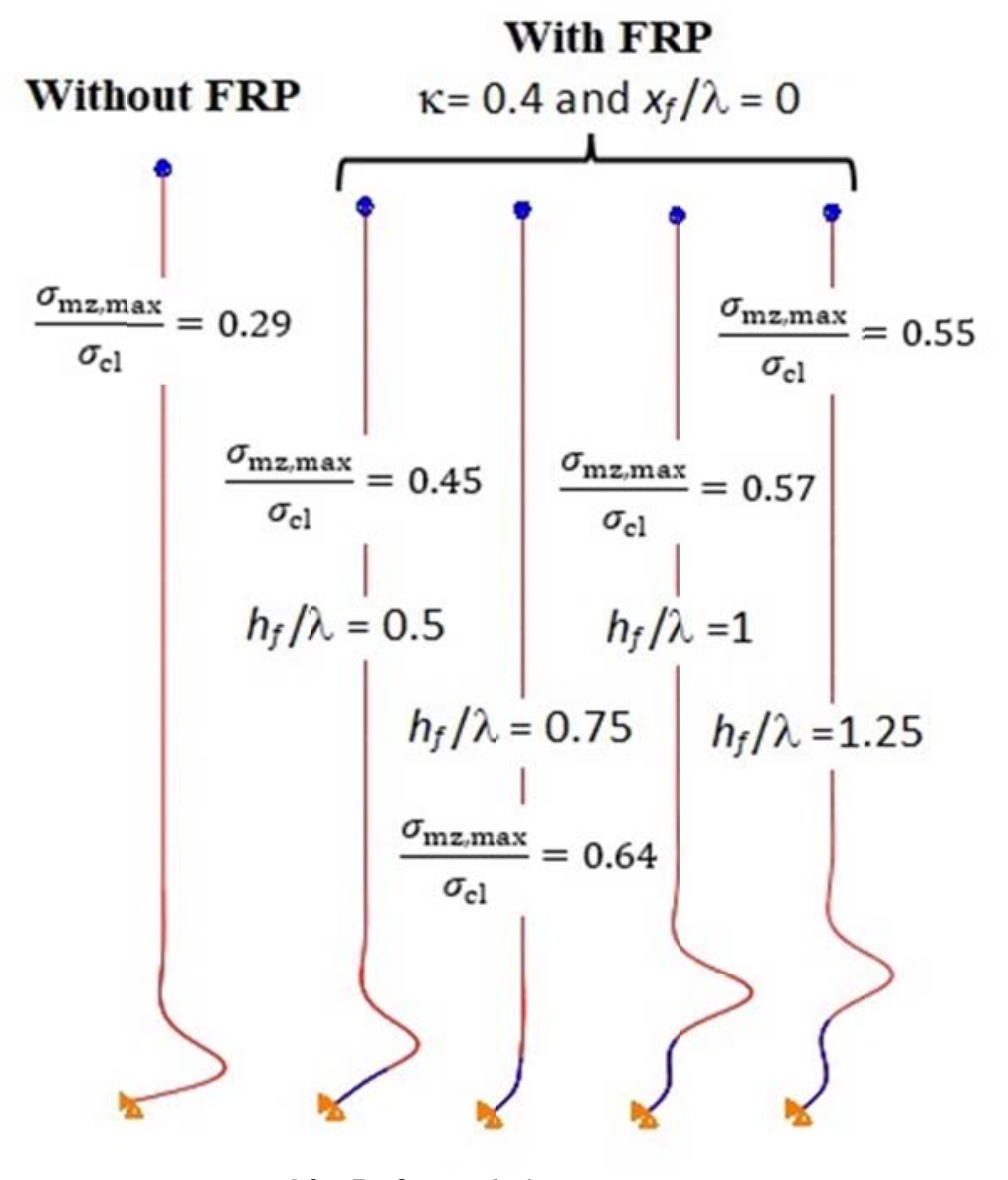

b) Deformed shapes

FIG. 5. Effect of FRP height $h_{f}\left(\mathrm{k}=0.4\right.$ and $\left.x_{f} / \lambda=0\right)$.

The effect of the location of the lower end of the FRP sheet (starting level ratio $x_{f} / \lambda$ ) was next explored leading to the results shown in Fig. 6 . The stiffness ratio $\kappa$ and the height ratio $h_{f} / \lambda$ were fixed at 0.4 and 0.75, respectively, assuming that the optima found in Figs 4 and 5 might be little affected by a change in the starting level. When the base of the FRP strip is raised ( $x_{f}$ increased) as can be seen from Fig. 6a, the buckling strength progressively decreases. Figure $6 \mathrm{~b}$ shows the deformed shapes at the end of the analysis for the cases in Fig. 6a. The elephant's foot buckle is obvious when no FRP is installed. When the FRP is added starting at the base $\left(x_{f} / \lambda=0\right)$, the elasto-plastic elephant's foot buckle is eliminated: the failure is changed to an elasto-plastic collapse in a very small zone near the bottom boundary where the radial displacement does not exceed the membrane deformation. When the FRP sheet position is raised by even a small amount relative to the linear bending half wavelength (e.g. $x_{f} / \lambda=0.1$ and $x_{f} / \lambda=0.25$ ), two buckles are formed at collapse: a smaller one adjacent to the bottom boundary and a larger one above the FRP strengthened zone. When the FRP strip location is raised further, the sizes of these two buckles is gradually reversed: a smaller one above the FRP and a larger one below it (allowing the elasto-plastic deformation to form again at the base). This also explains the dramatic fall in capacity seen in in Fig. $6 \mathrm{a}$ for the cases with $x_{f} / \lambda=0.5$ and $x_{f} / \lambda=0.75$. If the FRP location is further raised, the strengthening effect of the FRP disappears as the un-strengthened mode resumes its former role. 


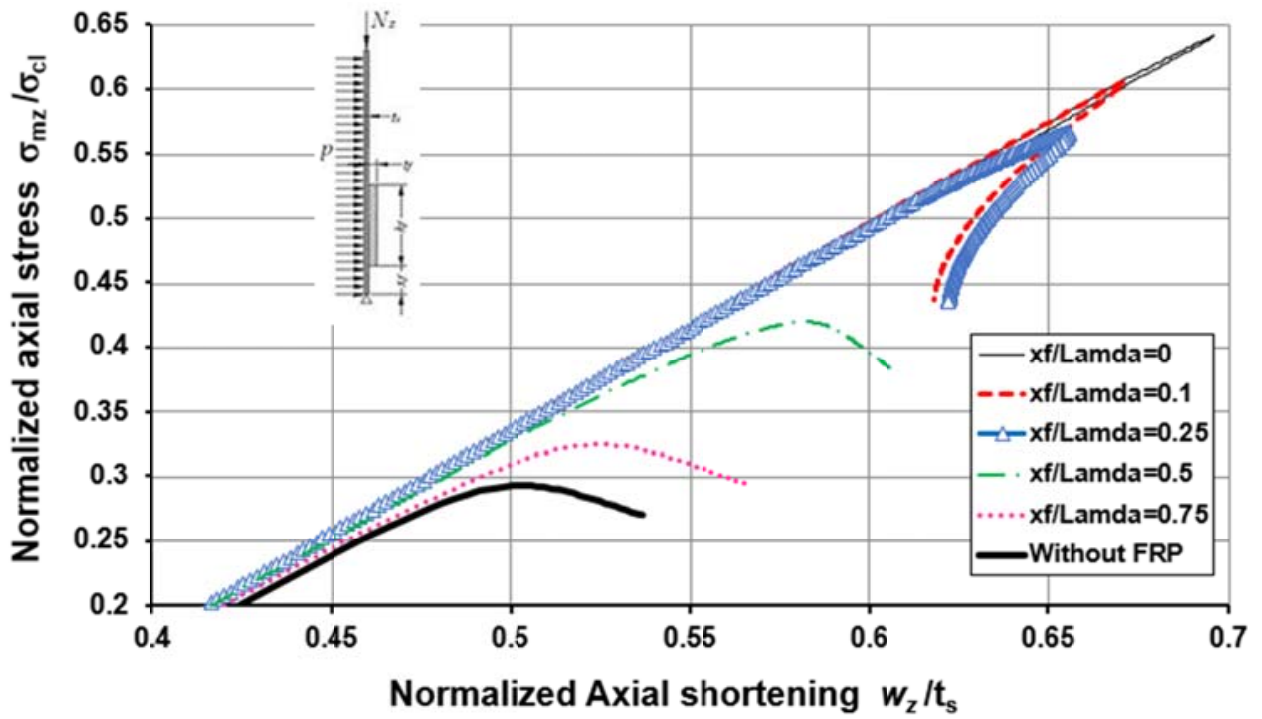

a) Stress - axial shortening curves

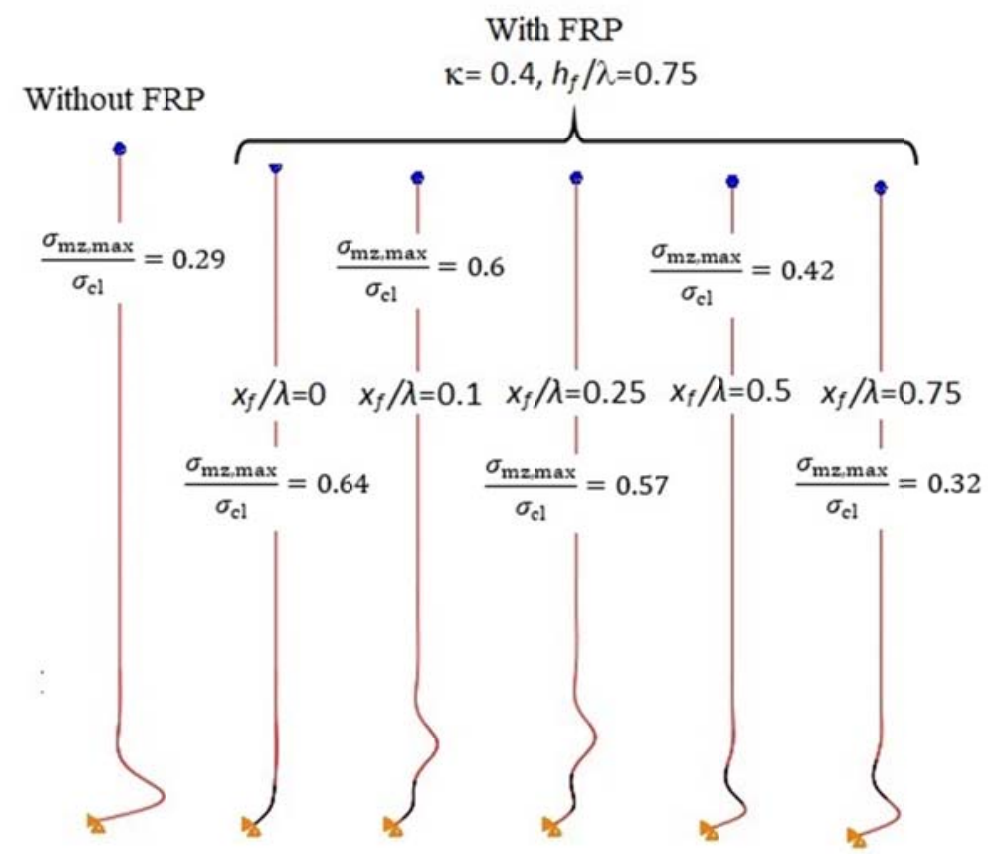

b) Deformed shape

FIG. 6. Effect of starting level of FRP $\left(\mathrm{K}=0.4\right.$ and $\left.h_{f} / \lambda=0.75\right)$. 


\section{FRP parameters for achieving the highest loading capacity}

The FRP sheet is intended to act as a circumferential restraint on the area where the von Mises stresses are at their maximum leading to the local elasto-plastic collapse (see Fig. 1). This local circumferential restraint aims to increase the axial capacity at elastic-plastic collapse, potentially up to the elastic buckling strength of the shell. It may be noted that it is possible to increase the elastic buckling strength of the shell by wrapping FRP around the whole shell, but this is usually neither necessary nor economical in practice. Therefore, the objective of this research is to enhance the elephant's foot buckling capacity through local FRP strengthening within the small zone near the bottom boundary. The maximum achievable strengthening that FRP can give is thus to enhance the axial load capacity either to the elastic buckling strength (as shown by the lines marked with diamonds, circles or triangles in Fig. 7 for fabrication quality classes A, B or C), or else to the membrane yield strength. This goal is potentially achievable by preventing an elephant's foot buckle from occurring before one of these other failure modes is reached.

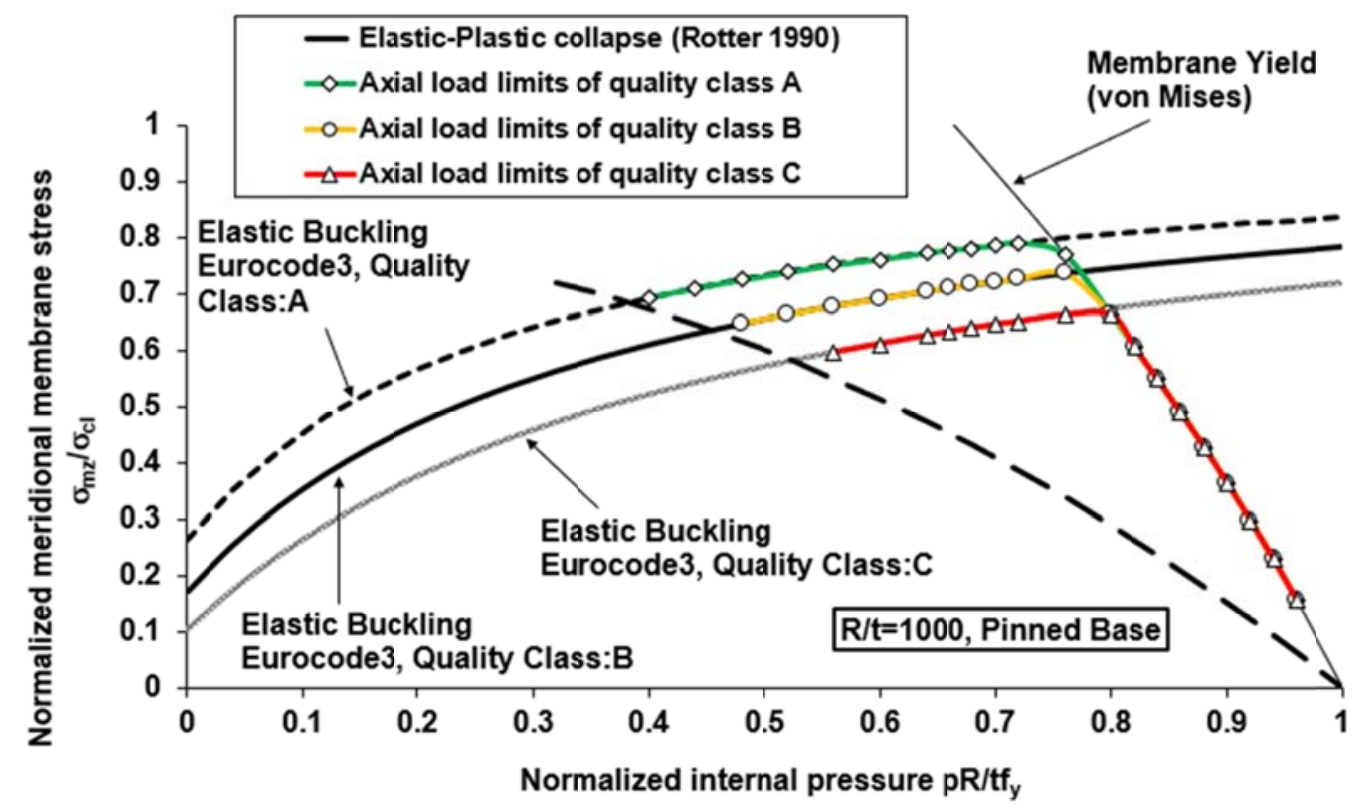

FIG. 7. Membrane axial stress limits by using local FRP strengthening. 


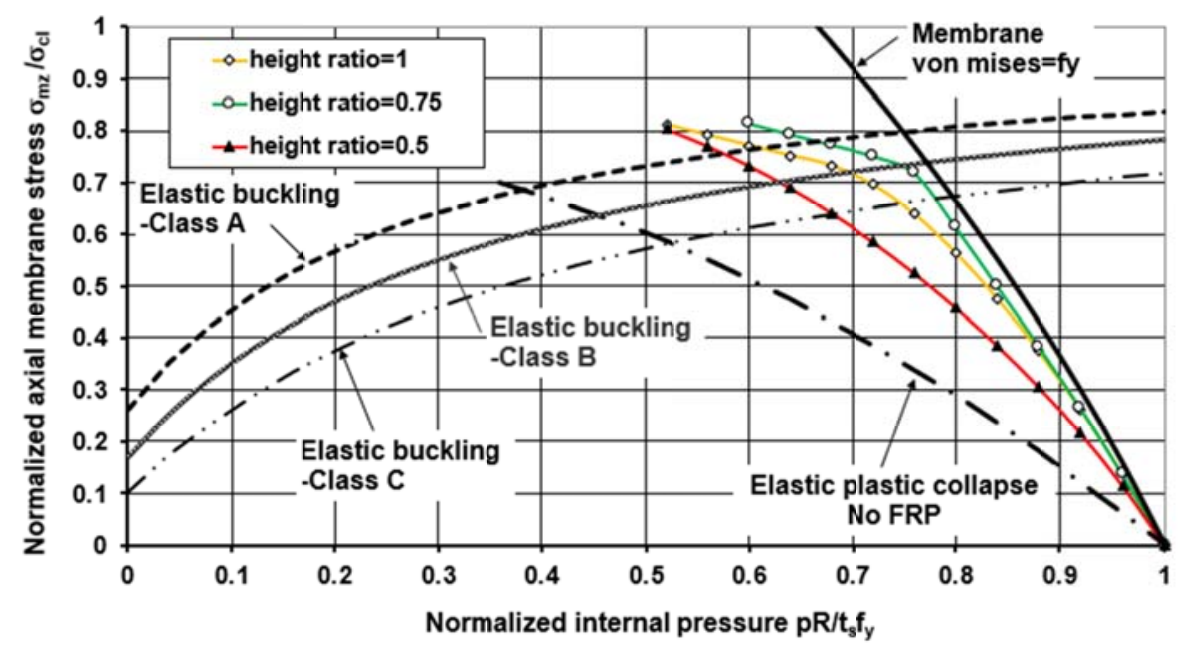

FIG. 8. Effect of height ratio on buckling strength $\left(\mathrm{k}=0.46\right.$ and $\left.x_{f} / \lambda=0\right)$.

The three parameters of the FRP strengthening that determine the effectiveness of the method are $t_{f}, h_{f}$ and $x_{f}$. In this study, two of these parameters were fixed and the third one was varied until its optimum value was found. This was undertaken for each parameter in turn. For example, Fig. 8 shows the buckling strength for three different height ratios for the reference cylindrical shell and FRP, when $\kappa=0.46$ and $x_{f} / \lambda=0$. It is seen that a FRP height ratio around $h_{f} / \lambda=0.75$ achieves the maximum enhancement of the buckling strength. It should be noted that the axisymmetric FE model predicts only the axisymmetric elastic-plastic collapse failure (elephant's foot buckling) of perfect cylinders, not the non-axisymmetric elastic bifurcation failure. This is why some of the predicted elastic-plastic collapse strengths are higher than the elastic buckling strength, plotted using Eq. 8.

A more comprehensive study was next undertaken, examining the variation of the buckling strength with the FRP stiffness ratio $\kappa$ for different levels of internal pressure. The outcome (Fig. 9) shows that a different amount of FRP is required to achieve the maximum strength at different pressure levels. When the internal pressure is very high $\left(c=p R / t f_{y}>0.85\right)$, the required amount of FRP to achieve the maximum strength is unaffected by the internal pressure at about $\kappa=0.3$, but when the internal pressure is reduced, more FRP is required to achieve the maximum strength.

The stress levels at which elastic buckling may be expected for different classes of fabrication quality are also shown. These buckling stresses, which depend on imperfections far from the boundary, are hereafter treated as cut-off levels above which the local FRP strengthening cannot increase the buckling capacity. 


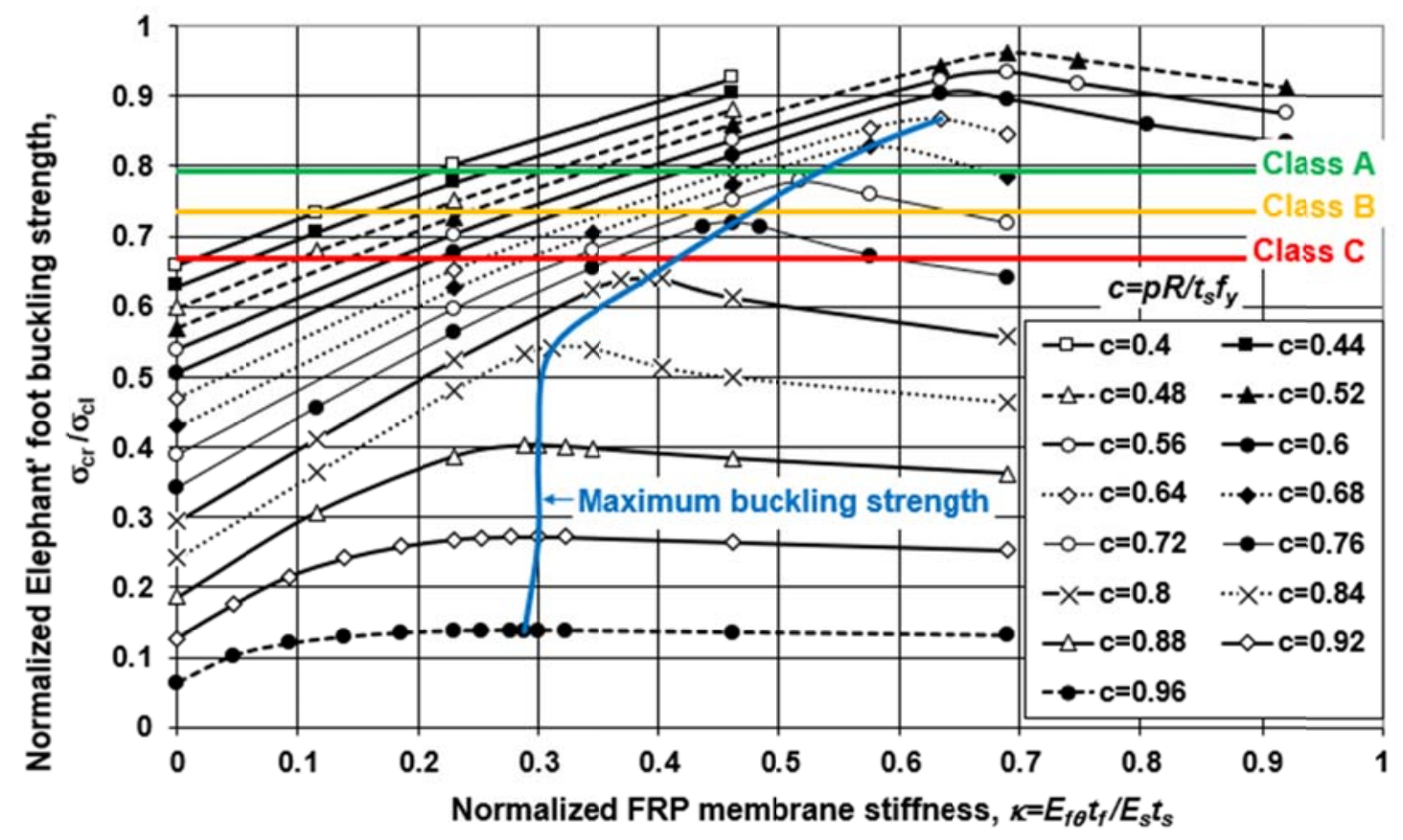

FIG. 9. Effect of FRP membrane stiffness on the buckling strength at different internal pressures $\left(h_{f} / \lambda=\right.$ 0.75 and $\left.x_{f} / \lambda=0\right)$.

The study was next extended again to identify the optimum values for the amount of FRP, its height $h_{f}$ and the base starting level $x_{f}$, each as a function of the relative internal pressure in the cylinder. For each pressure level and fabrication quality class, an extensive iterative procedure with numerous FE runs was undertaken to find the optimum values of the three parameters (normalised FRP stiffness ratio $\kappa$ (Eq. 12), FRP sheet height $\bar{h}_{f}=\pi h_{f} / \lambda_{\mathrm{b}}$ and starting level $\bar{x}_{f}$ $\left.=\pi x_{f} / \lambda\right)$ to achieve the maximum elephant's foot buckling strength. The internal pressure $p$ is normalised here against the von Mises membrane stress, which better represents membrane yielding:

$$
\bar{p}=\frac{p R}{t_{s} \sigma_{v M 0}}
$$

in which $\sigma_{v M 0}$ is the von Mises membrane stress

$$
\sigma_{v M 0}=\sqrt{\sigma_{m z}^{2}-\sigma_{m z} \sigma_{m \theta}+\sigma_{m \theta}}
$$

where $\sigma_{m z}$ and $\sigma_{m \theta}$ are the simple axial and circumferential membrane stresses far from the boundary respectively:

$$
\begin{array}{r}
\sigma_{m z}=\frac{N_{z}}{t_{s}} \\
\sigma_{m \theta}=\frac{p R}{t_{s}}
\end{array}
$$


In the normalised FRP height parameter $\left(\bar{h}_{f}\right)$, the meridional bending half-wavelength has been re-evaluated as $\bar{\lambda}_{b}$ to account for the effect of the FRP on this half-wavelength in the section where FRP is attached (Batikha et al. 2007b and Batikha et al. 2009):

$$
\bar{\lambda}_{b}=2.444 \sqrt{R t_{b}}
$$

in which $t_{b}$ is a modified shell thickness accounting for the FRP circumferential membrane stiffness $(\kappa)$ into consideration:

$$
t_{b}=\frac{t_{s}}{\sqrt{1+\kappa}}
$$

The results are shown in Figs 10-12. Figure 10 shows that when the internal pressure is low (e.g. $\bar{p}<0.65$ for Class A), elastic buckling dominates and FRP strengthening cannot increase the buckling strength. For intermediate pressures (e.g. $0.65<\bar{p}<0.75$ for Class A), FRP strengthening is required to raise the elephant's foot buckling strength to a level above the elastic buckling strength of the un-strengthened section of the shell so that the final failure mode is elastic buckling above the base boundary. The amount of FRP required increases with increasing pressure in this range, but it also depends on the elastic buckling resistance to be achieved, which in turn depends on the amplitude of the imperfections elsewhere in the shell, so the curves for FRP requirement depend on the fabrication quality class of the cylindrical shell.

When the pressure is even higher (e.g. $\bar{p}>0.75$ for Class A), elastic-plastic elephant's foot buckling dominates and FRP strengthening can increase the buckling strength up to the membrane yield strength. The amount of FRP required to achieve becomes less as the pressure increases further.

Figure 11 shows the optimum normalised FRP height $\bar{h}_{f}$. It increases at higher internal pressures, irrespective of whether elastic buckling or elephant's foot buckling dominates. Figure 12 shows that, for all cases, the optimum normalised FRP starting level $\bar{x}_{f}$ is lower at higher levels of normalised internal pressure $\bar{p}$. 


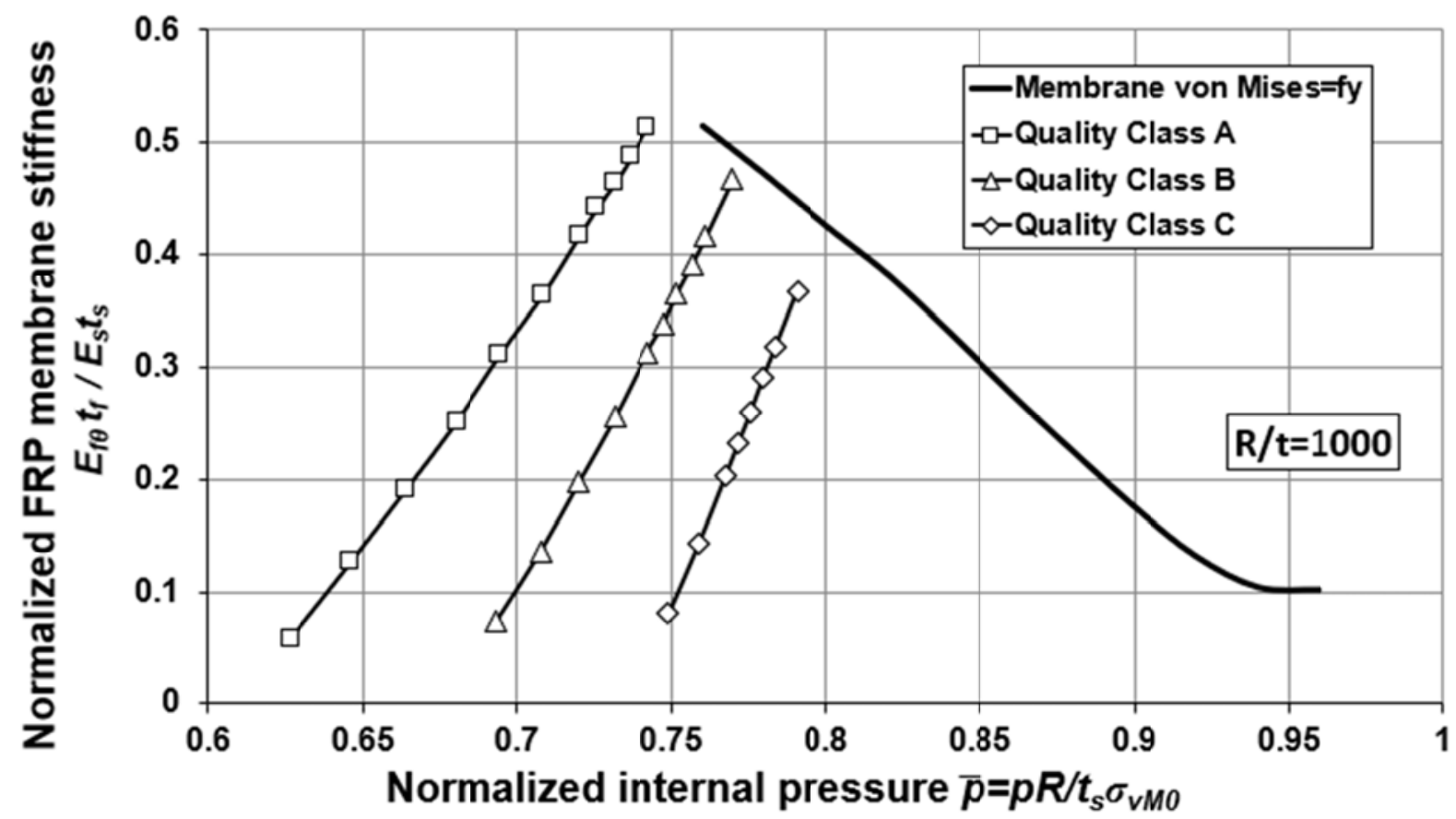

FIG. 10. Optimum FRP circumferential membrane stiffness, $\kappa$.

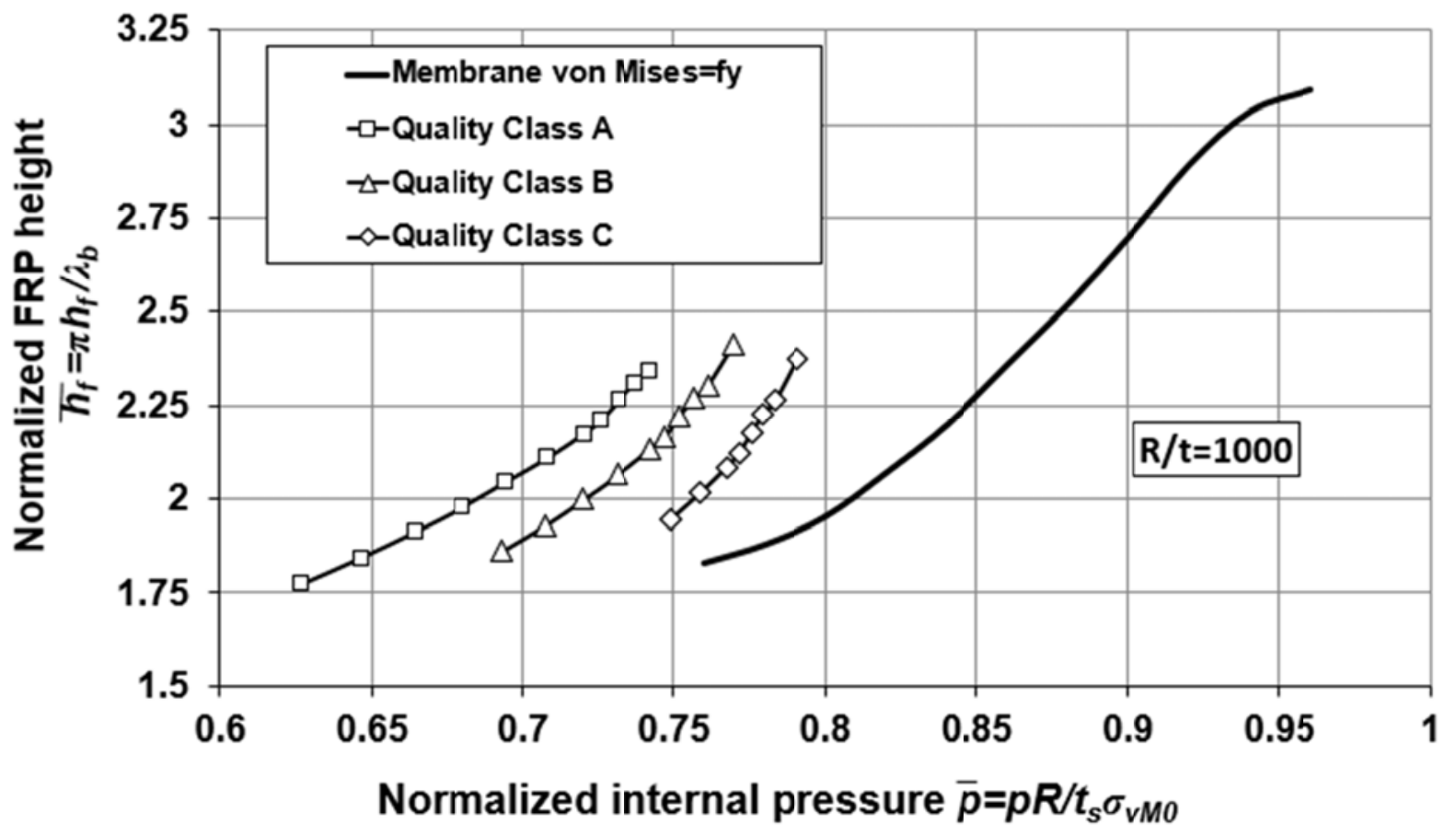

FIG. 11. Optimum FRP height, $h_{f}$ 


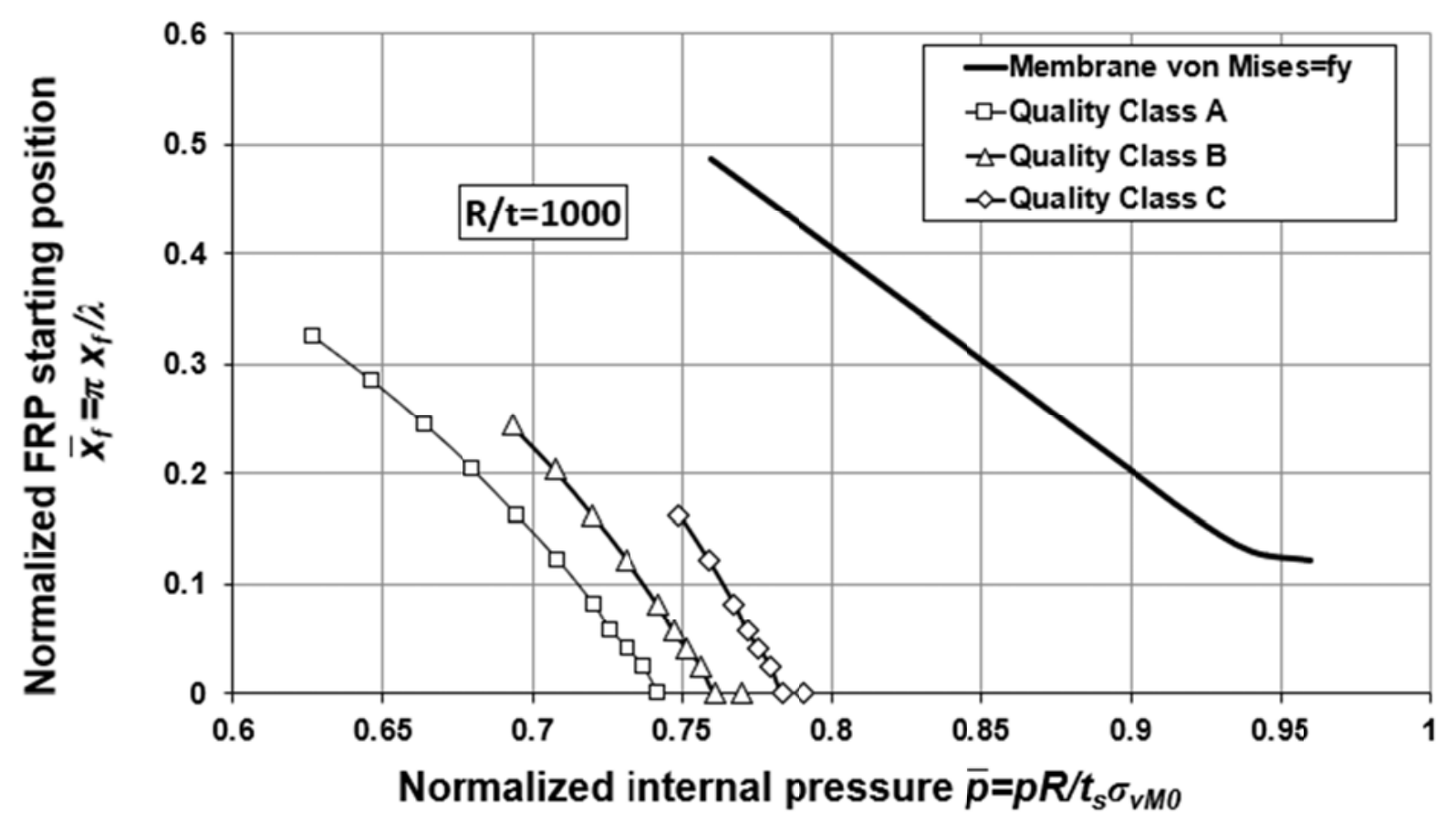

FIG. 12. Optimum FRP starting level, $x_{f}$

\section{Empirical formulas for the optimum FRP properties}

For all the FRP parameters shown in Figs 10-12, there are two regions for each parameter to achieve the maximum load capacity of the shell. At very high pressures, membrane yield according to von Mises (Eq. 14) is achievable. At moderate pressures, FRP strengthening can ensure that the elastic imperfect buckling strength (Eq. 8), which cannot be changed by the FRP, is higher than that for any potential elephant's foot buckle (Fig.8).

\subsection{The required parameters for membrane yield}

The images in Figs 10-12 indicate that in the region controlled by membrane yield there is an approximately exponential relationship between each of the parameters $\kappa, \bar{h}_{f}$ and $\bar{x}_{f}$ with the internal pressure $\bar{p}$ (Eq. 13). Empirical relationships giving a close fits have the form:

$$
A-\cos (B \bar{p}) e^{(B \bar{p}-C)}
$$

in which the regression coefficients $\mathrm{A}, \mathrm{B}$ and $\mathrm{C}$ are given in Table 2. 
Table 2. The coefficients in Eq. 19 for the optimum values of the three FRP parameters

\begin{tabular}{|l|c|c|c|}
\hline Optimum value of the FRP parameter & \multicolumn{3}{|c|}{ Coefficients } \\
\cline { 2 - 4 } & A & B & C \\
\hline$\kappa=\frac{E_{f \theta} t_{f}}{E_{S} t_{s}}=A-\cos (B \bar{p}) e^{(B \bar{p}-C)}$ & 0.66 & 7.4 & 7.3 \\
\hline$\overline{h_{f}}=\pi h_{f} / \lambda_{\mathrm{b}}=A-\cos (B \bar{p}) e^{(B \bar{p}-C)}$ & 1.79 & 10.5 & 9.6 \\
\hline$\overline{x_{f}}=\pi x_{f} / \lambda=A-\cos (B \bar{p}) e^{(B \bar{p}-C)}$ & 0.59 & 7.3 & 7.5 \\
\hline
\end{tabular}

\subsection{The required parameters for elastic buckling part}

For the elastic buckling region, the optimum values of the FRP parameters can be closely modelled by:

$$
A \pm e^{(B \bar{p}-C)}
$$

where the coefficients $\mathrm{A}, \mathrm{B}$ and $\mathrm{C}$ were obtained by regression for each fabrication quality class and are given in Table 3 .

Table 3. Coefficients in Eq. 20 for elastic buckling

\begin{tabular}{|l|l|l|l|l|l|l|l|l|l|}
\hline \multirow{2}{*}{ FRP Parameter } & \multicolumn{3}{|l|}{ Class A } & \multicolumn{3}{l|}{ Class B } & \multicolumn{2}{l|}{ Class C } \\
& A & B & C & A & B & C & A & B & C \\
\hline$\kappa=\frac{E_{f \theta} t_{f}}{E_{s} t_{s}}=A \pm e^{(B \bar{p}-C)}$ & -1.31 & 2.48 & 1.24 & -1.1 & 3.81 & 2.49 & -1.72 & 3.64 & 2.1 \\
\hline$\overline{h_{f}}=\pi h_{f} / \lambda_{\mathrm{b}}=A \pm e^{(B \bar{p}-C)}$ & 1.47 & 8.8 & 6.7 & 1.59 & 14 & 11 & 1.66 & 21.8 & 17.6 \\
\hline$\overline{x_{f}}=\pi x_{f} / \lambda=A \pm e^{(B \bar{p}-C)}$ & 0.64 & 6.07 & 1.96 & 0.65 & 6.87 & 5.65 & 1.02 & 5.07 & 3.96
\end{tabular}

\subsection{Validation of the empirical formulas}

Comparisons between the identified optimum values of the FRP parameters from the FE analyses and the empirical formulas (Eqs 19 and 20) are shown in Figures 13-15, where the close fits are evident. The sensitivity of selecting values that differ from the optimum ones is illustrated in Figs 16 and 17 for quality Class A as an example. It is clear that even small variations from the optimum values lead to noticeable strength losses. Significant departures from the optimum FRP stiffness $\kappa$ (Fig. 16) clearly lead to very poor outcomes, whilst the elastic buckling zone is sensitive to even small changes. In the membrane yield zone, the buckling strength is very sensitive to the FRP height $\bar{h}_{f}$ (Fig. 17) with even a $10 \%$ change in height producing quite significant strength losses. 


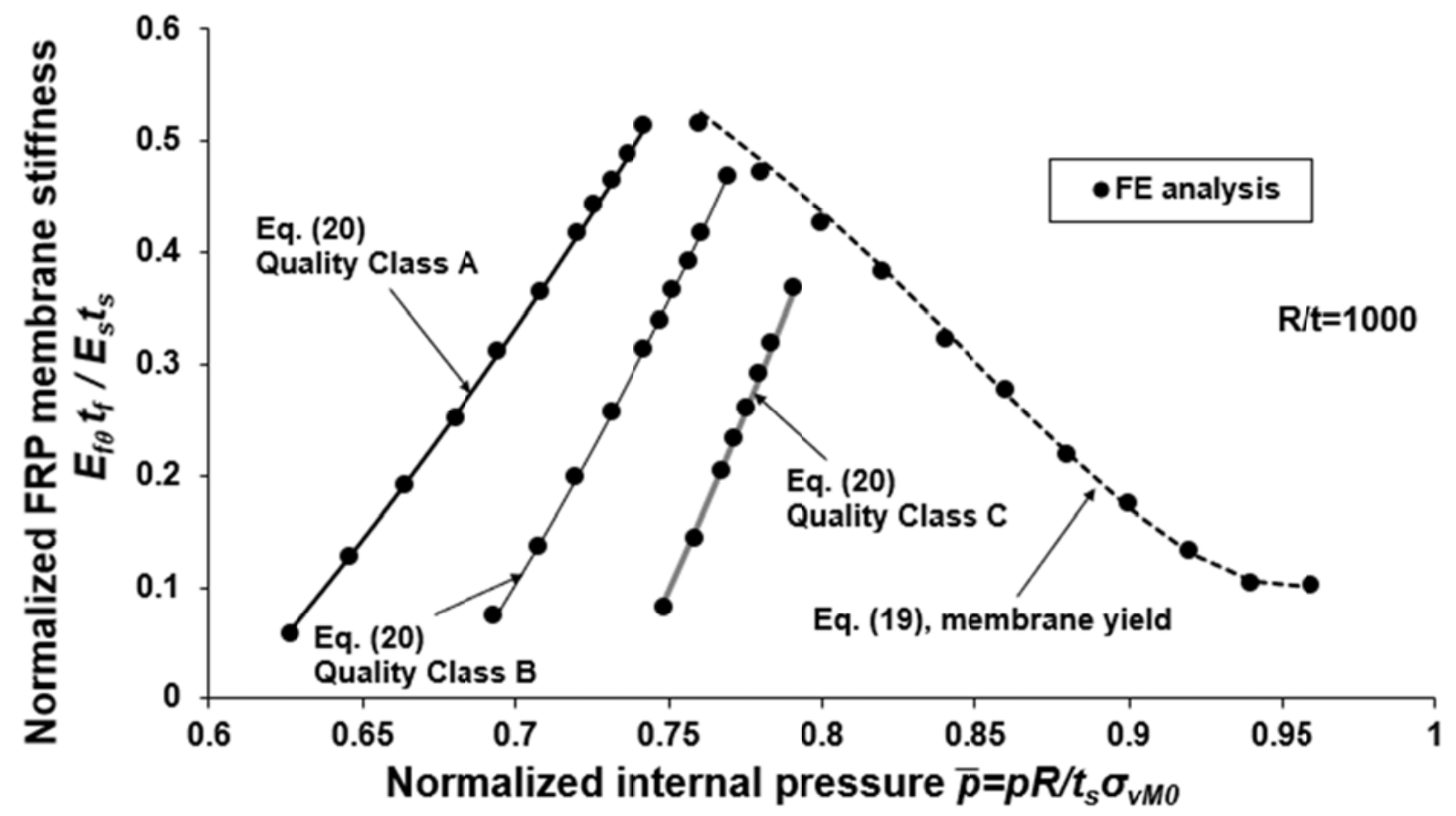

FIG. 13. The optimum FRP circumferential membrane stiffness $\kappa$.

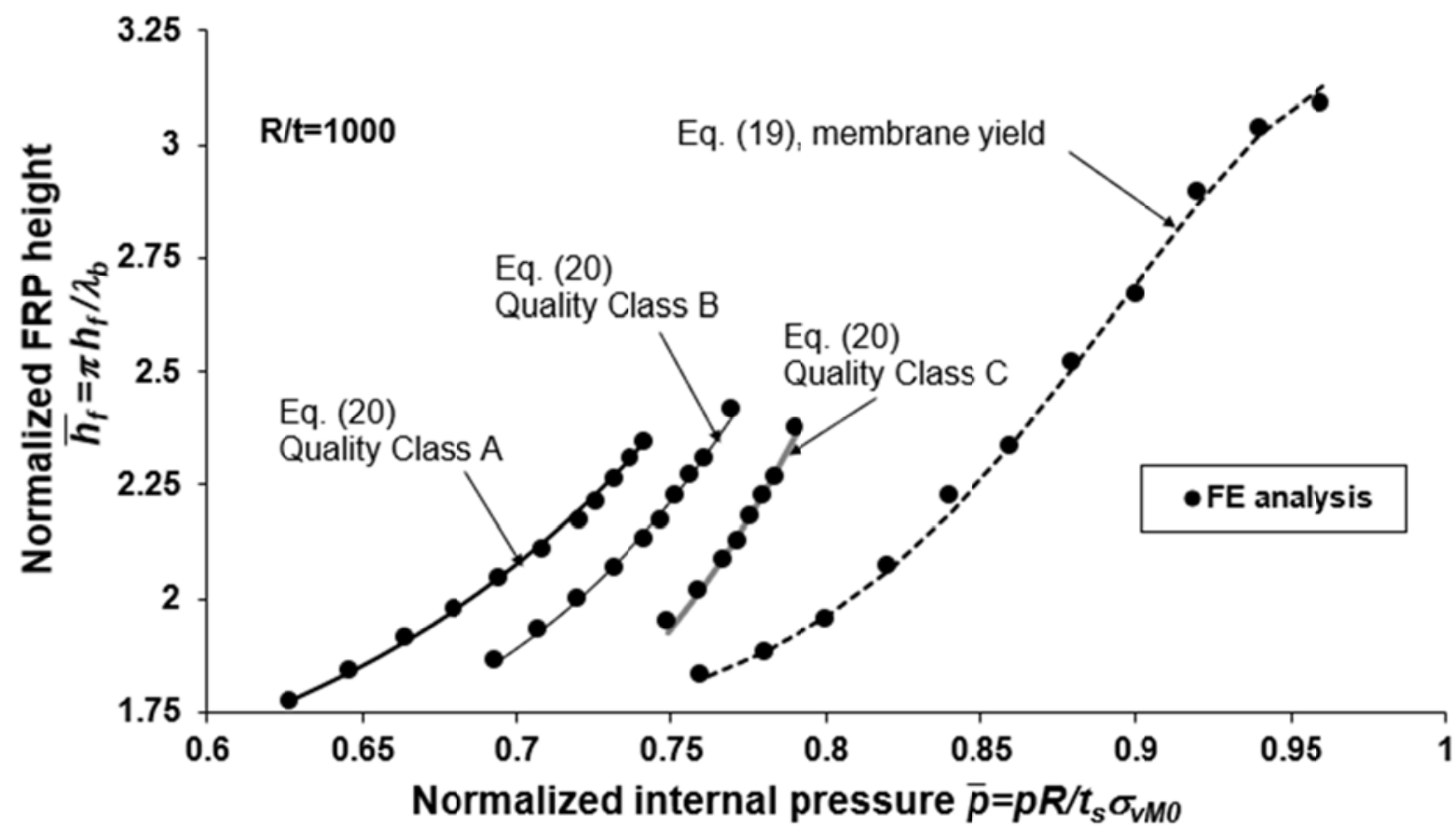

FIG. 14. The optimum FRP height $h_{f}$ 


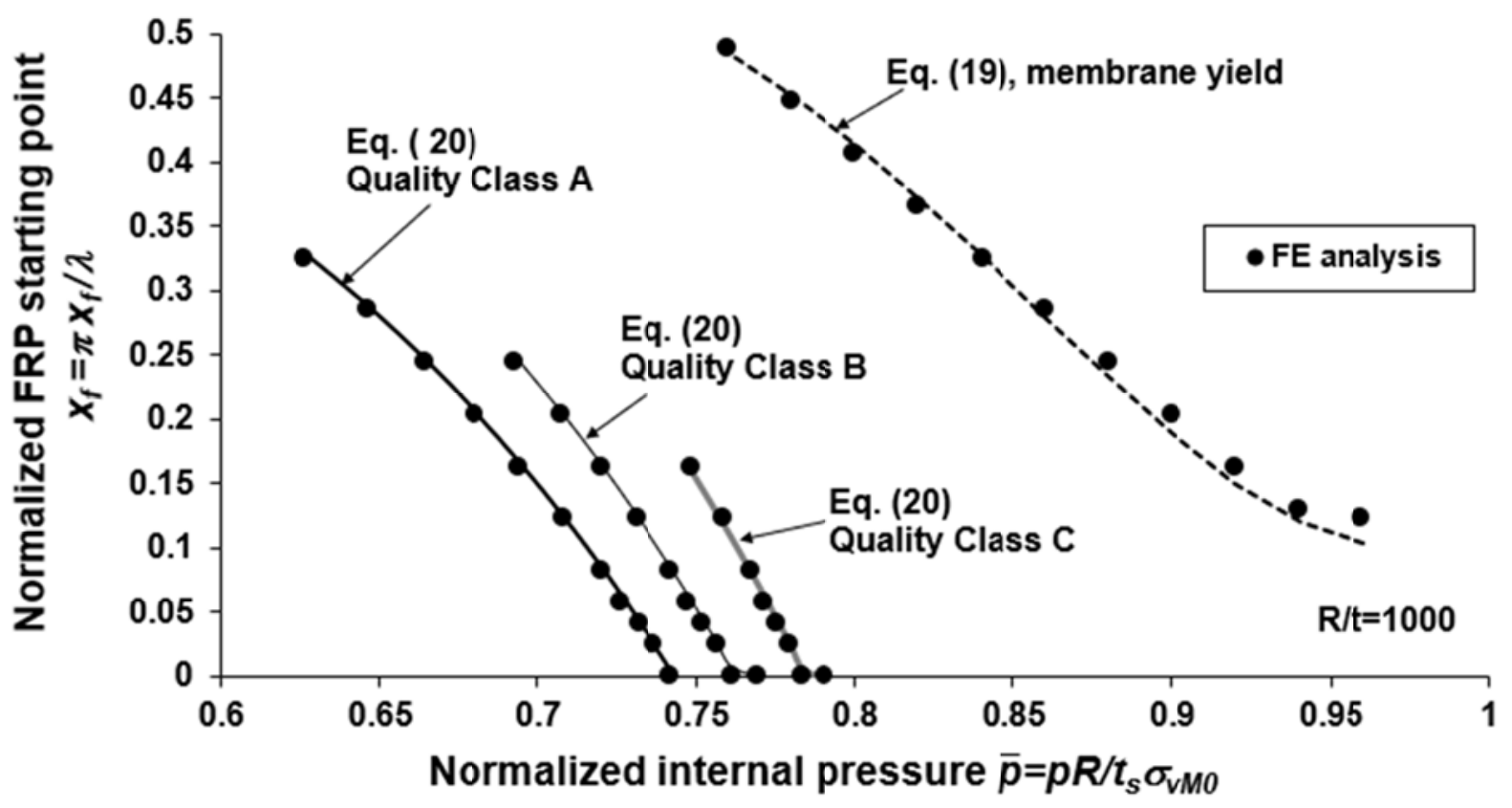

FIG. 15. Optimum FRP starting level $x_{f}$.

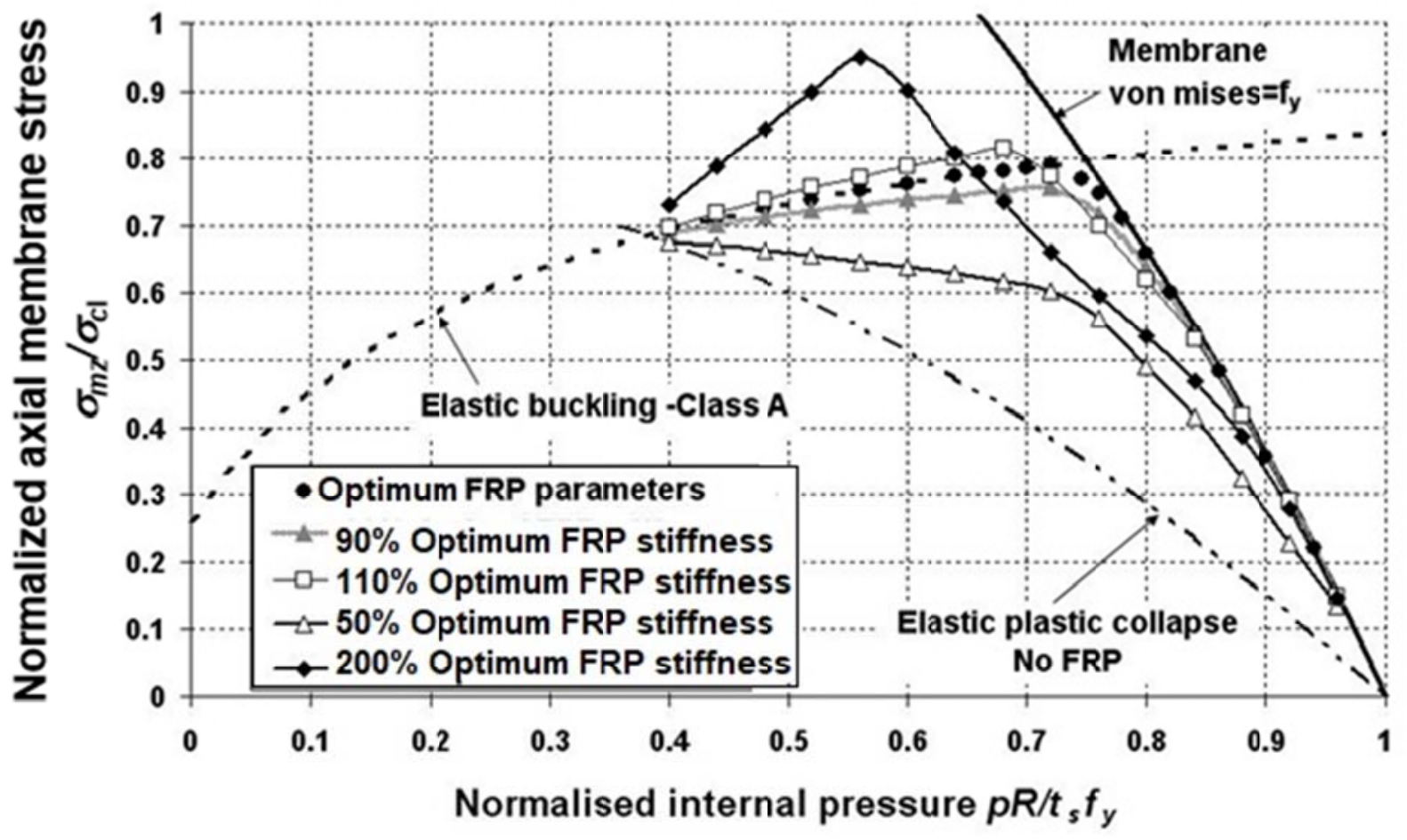

FIG. 16. Sensitivity of buckling strength to FRP stiffness. 


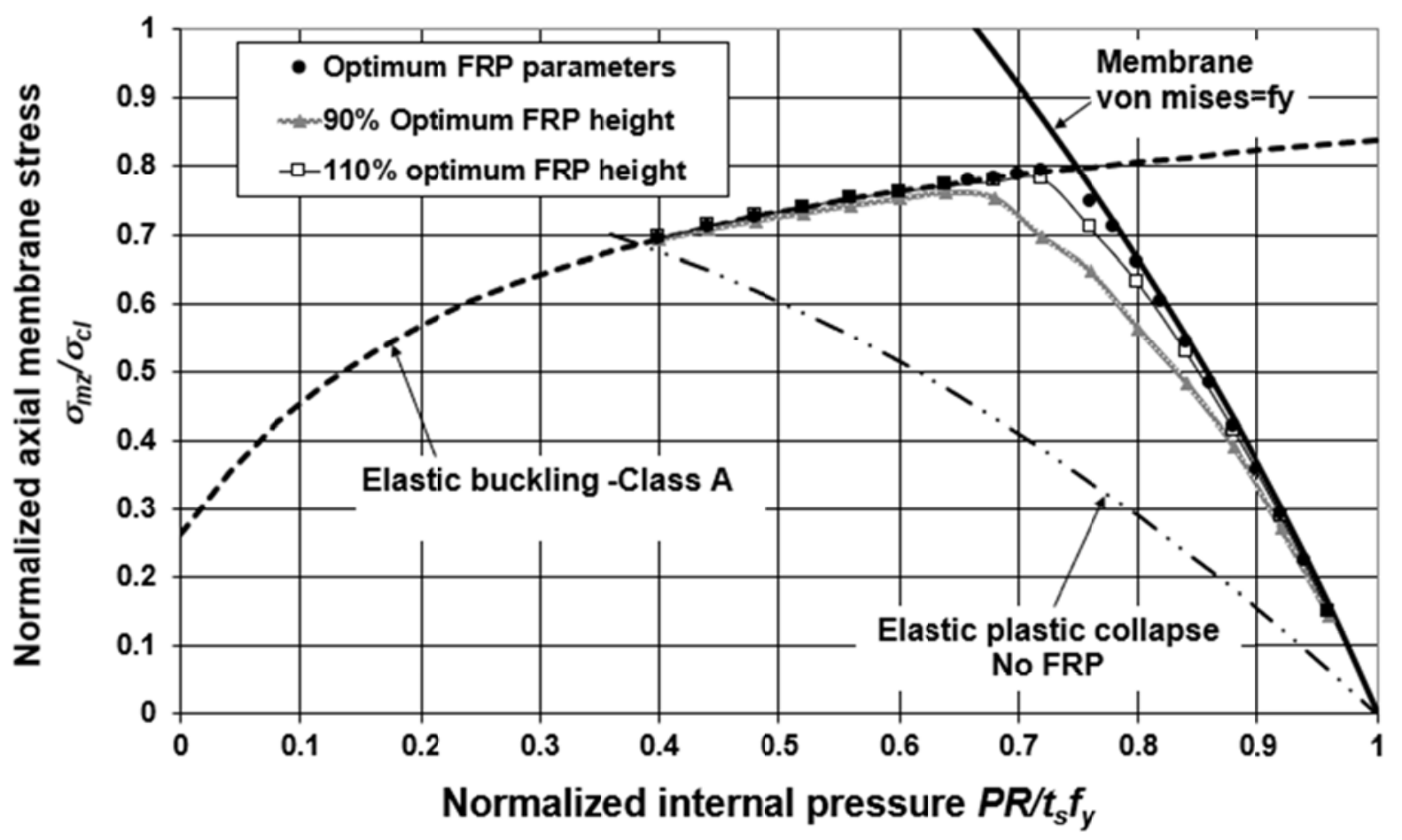

FIG. 17. Sensitivity of buckling strength to FRP height.

\subsection{A worked example}

The empirical formulas were applied to the cylinder described in Section 2 using the FRP properties given in Section 4.3. A high internal pressure of $0.2 \mathrm{~N} / \mathrm{mm}^{2}$ was applied corresponding to a normalised internal pressure of $\bar{p}=0.8$ (Eq. 13). Using Eq. 19, the FRP parameters were chosen at their optimum values of thickness $\left(t_{f}\right)$, height $\left(h_{f}\right)$ and starting level $\left(x_{f}\right)$ at $1.85 \mathrm{~mm}, 220 \mathrm{~mm}$ and $50 \mathrm{~mm}$ respectively. A comparison between the behaviour of the cylinder strengthened using truly optimum values of the parameters with that of the best choice parameters in Fig. $6\left(\kappa=0.4, h_{f} / \lambda=0.75\right.$ and $\left.x_{f} / \lambda=0\right)$ is shown in Figure 18 . The truly optimum values lead to a slight improvement in strength. 


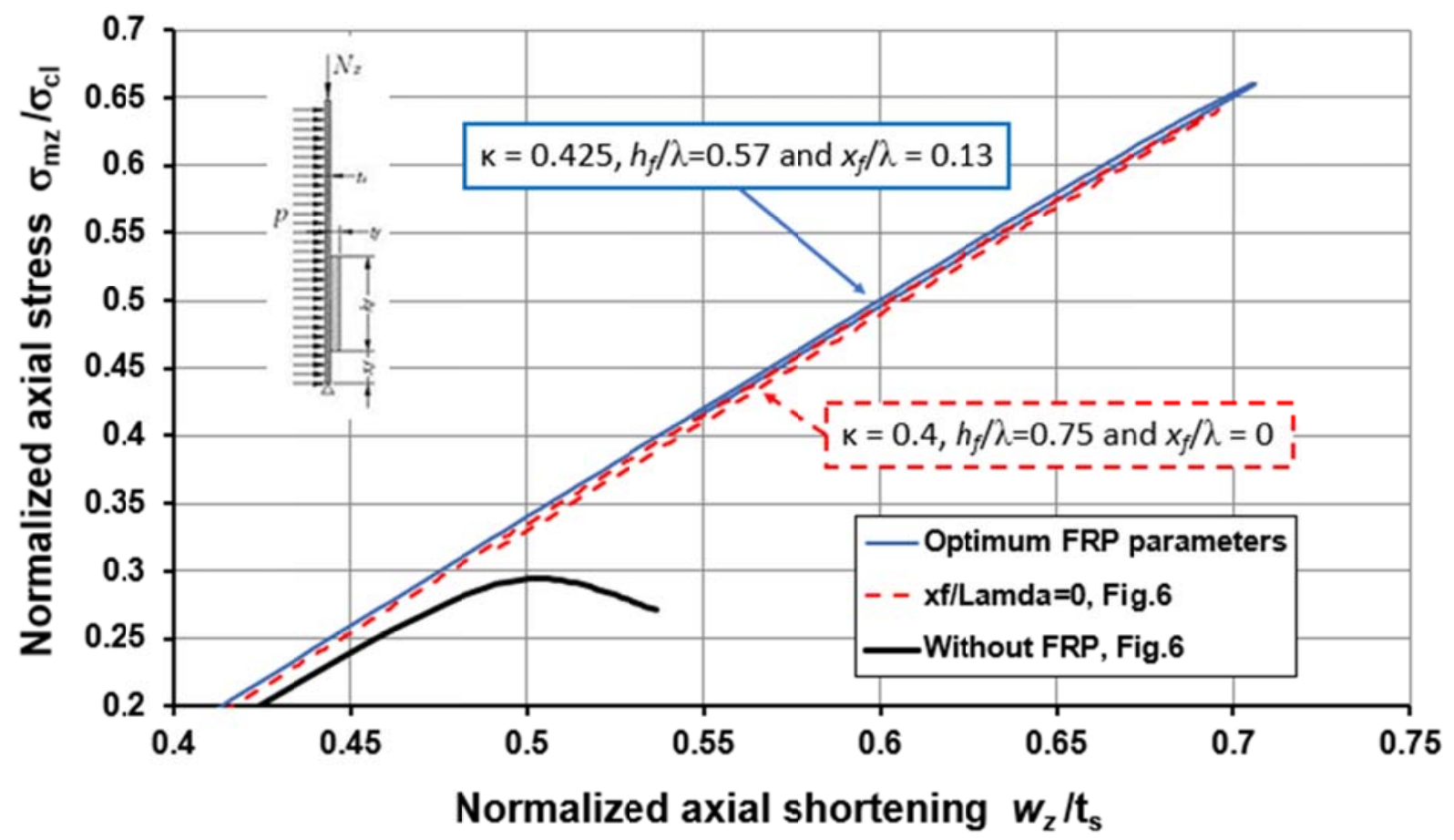

FIG. 18. Behaviour of the reference cylinder strengthened using optimum FRP parameters and the ones given in Fig. 6.

\section{Conclusions}

This paper has presented an investigation into the use of FRP to strengthen a thin cylindrical shell against buckling under axial compression when subject to internal pressure. Geometrically and Materially Non-linear Analysis (GMNA) was used to assess the increase in buckling strength for an FRP-strengthened cylindrical steel shell. The different kinds of buckling behaviour, and the domains over which they are critical have been explored and clearly described. The optimum size and location of an FRP sheet required to prevent elephant's foot buckling in a pressurised cylindrical shell has been identified. Whilst the study has focussed on a shell with a radius to thickness ratio of 1000 , all the results have been presented in dimensionless form, with due consideration of the fabrication quality classes of the shell structure. A set of empirical dimensionless formulas have been proposed to identify the optimum amount and placement of FRP strengthening.

It has been shown that the strengthening effect of the FRP is very sensitive to its thickness, height and location, and optimum values for all three have been identified for the full range of axial loads and internal pressures. It has been shown that small variations from the optimum values lead to significantly reduced strengths. The sensitivity of the buckling load to the thickness and height of the FRP band has been shown to be very significant, whilst the distance above the base at which the FRP band should start is much less. The empirical formulas for optimum strengthening are sufficiently general to be directly adopted in practical designs. 


\section{References}

ABAQUS/Standard User's Manual, Version 6.12-1 (2012). ABAQUS Inc, USA.

Batikha, M., Chen, J.F. and Rotter, J.M. (2007a) Numerical modelling of shells repaired using FRP. Proc., 3rd Int. Conf. on steel and composites structures, ICSCS07, 30July-1 August, Manchester, UK, 1065-1069.

Batikha, M., Chen, J.F. and Rotter, J.M. (2007b) FRP strengthening of metallic cylindrical shells against elephant's foot buckling. Proc., Conf. on Advanced composites in Construction, ACIC 07, 2-4 April, Bath, UK, 157-164.

Batikha M., Chen J.F., Rotter J.M. and Teng J.G. (2009) Strengthening metallic cylindrical shells against elephant's foot buckling with FRP. Thin-Walled Structures 47:1078-1091.

Cao Q.S., Yang Zhao Y. and Zhang R. (2018) Wind induced buckling of large circular steel silos with various slenderness. Thin-Walled Structures 130:101-113.

Chen, J. F., Rotter, J. M. and Teng, J.G. (2005) Strengthening silos and tanks against elephant's foot buckling. Proc., 4th Int. Conf. on Advances in Steel Structures, ICASS 05, 13-15 June, Shanghai, China, 459-466

Chen, J. F., Rotter, J.M. and Teng, J.G. (2006) A simple remedy for elephant's foot buckling in cylindrical silos and tanks. Advances in Struct. Eng., 9(3):409-420.

Djermane M., Zaoui D., Labbaci B. and Hammadi F. (2014) Dynamic buckling of steel tanks under seismic excitation: Numerical evaluation of code provisions. Engineering Structures 70:181-196.

ECCS (2008) Buckling of steel shells - European design recommendations, the 5th Edition, European Convention for Constructional Steelwork. Brussels, Belgium.

EN 1993-1-6 (2007) Eurocode 3: Design of steel structures-Part 1-6: Strength and stability of shell structures. Brussels: CEN.

EN 1993-4-1 (2007) Eurocode 3 - Design of steel structures - Part 4-1: Silos. Brussels: CEN.

EN 1998-4 (2006) Eurocode 8 - Design of structures for earthquake resistance - Part 4: Silos, tanks and pipelines. Brussels: CEN.

Kildashti K., Mirzadeh N. and Samali B. (2018) Seismic vulnerability assessment of a case study anchored liquid storage tank by considering fixed and flexible base restraints. Thin-Walled Structures 123:382-394.

Lu Y., Li N. and Li S. (2014) Behavior of FRP-Confined Concrete-Filled Steel Tube Columns. Polymers 6: 1333-1349. 
NZS/BS 2654:1989 (1989) Specification for manufacture of vertical steel welded nonrefrigerated storage tanks with butt-welded shells for the petroleum industry. Standards New Zealand, Wellington, New Zealand.

Punitha Kumar A. and Senthil R. (2016 a) Axial Behaviour of CFRP-Strengthened Circular Steel Hollow Sections. Arab J Sci Eng 41:3841-3850.

Punitha Kumar A. and Senthil R. (2016 b) Behavior of CFRP Strengthened CHS under Axial Static and Axial Cyclic Loading. KSCE Journal of Civil Engineering 20(4):1493-1500.

Rotter, J.M. (1985a) Bending theory of shells for bins and silos. Design of Steel bins for the Storage of Bulk Solids, School of Civil and Mining Engineering, University of Sydney, pp 71-81.

Rotter, J.M. (1985b) "Buckling of Ground-Supported Cylindrical Steel Bins under Vertical Compressive Wall Loads", Proc., Metal Structures Conference, Institution of Engineers Australia, Melbourne, May 1985, pp 112-127.

Rotter J.M. (1989) Stress amplification in unstiffened cylindrical steel silos and tanks. Institution of Engineers, Australia, Civil Engrg Transactions, CE31(3), 142-148.

Rotter, J.M. (1990) Local collapse of axially compressed pressurized thin steel cylinders. $J$. Struct. Eng. 116(7):1955-1969.

Rotter, J.M. (2004). Cylindrical shells under axial compression. In: Buckling of thin metal shells, J.G. Teng and J.M. Rotter, eds., Spon press, London, 42-87.

Rotter J.M. (2006) Elephant's Foot Buckling in Pressurized Cylindrical Shells. Stahlbau, 75 (9):742-747.

Rotter, J.M. and Teng, J.G. (1989) Elastic stability of cylindrical shells with weld depressions. $J$. Struct. Eng. 115(5):1244-1263.

Rotter, J.M. and Zhang, Q. (1990) Elastic buckling of imperfect cylinders containing granular solids. J. Struct. Eng. 116(8): 2253-2271.

Riks, E. (1979) An incremental approach to the solution of snapping and buckling problems. Inter. J. of Solids and Structures 15(7):529-551.

Sobhana M.S., F.R. Rofooeia F.R. and Attari N.K.A. (2017) Buckling behavior of the anchored steel tanks under horizontal and vertical ground motions using static pushover and incremental dynamic analyses. Thin-Walled Structures 112: 173-183.

Teng, J.G., Chen, J.F., Smith, S.T. and Lam, L. (2002), FRP Strengthened RC Structures, John Wiley and Sons, Chichester, UK. 
Teng, J.G. and Chen, J.F. (2009), "Mechanics of debonding in FRP-plated RC beams", Proceedings of the Institution of Civil Engineers - Structures and Buildings, Vol. 162, No. SB5, pp335-345.

Teng J.G., Yub T. and Fernando D. (2012) Strengthening of steel structures with fiber-reinforced polymer composites. Journal of Constructional Steel Research 78:131-143.

Teng, J.G., Hu, Y.M. (2007). Behaviour of FRP-jacketed circular steel tubes and cylindrical shells under axial comparison. Construction and Building Materials, 21(4), 827-838.

Teng, J.G. and Hu, Y.M. (2004) Suppression of local buckling in steel tubes by FRP jacketing. Proc., 2nd Int. Conf. on FRP Composites in Civil Engineering. Adelaide, Australia, 8-10 December, 749-753.

Teng, G.J. and Rotter, J.M. (1992) Buckling of pressurized axisymmetrically imperfect cylinders under axial loads. J. Eng. Mech. 118(2): 229-247.

Timoshenko S. and Woinowsky-Krieger S. (1959) Theory of Plates and Shells. Mcgraw-Hill, New York.

Zhao Y., Cao Q.S. and Su L. (2013) Buckling design of large circular steel silos subject to wind pressure. Thin-Walled Structures 73: 337-349.

Zhu C.Y., YH Zhao Y.H. and Sun L. (2018) Seismic performance of FRP-reinforced concretefilled thin-walled steel tube considering local buckling. Journal of Reinforced Plastics and Composites 37(9):592-608. 